\title{
La organización administrativa de la investigación sanitaria en Andalucía. Algunas consideraciones en torno a la fallida proposición de ley de creación del Instituto Andaluz de Salud
}

\section{The public organization of healtcare research in Anda- lusia. On the failing draft bill creating the Andalusian Health Institute of Health}

\author{
Antonio Bueno Armïo* \\ Profesor Titular de Derecho Administrativo. \\ Universidad de Córdoba
}

\begin{abstract}
SUMARIO: I. Introducción: una proposición de ley para crear un Organismo público de investigación en materia sanitaria. II. Identificación de los entes a partir de los cuales se creaba el Instituto Andaluz de Salud: la Fundación Pública Andaluza Progreso y Salud y la Escuela Andaluza de Salud Pública, Sociedad Anónima. III. Otros entes del sector público andaluz dedicados a la investigación sanitaria pero no incluidos en el proceso de fusión y transformación. IV. La inadecuación de las formas jurídicas privadas para la prestación de los servicios públicos asignados a la Fundación Pública Andaluza Progreso y Salud y la Escuela Andaluza de Salud Pública, S.A. V. La adecuación de las formas jurídicas propuestas para el Instituto Andaluz de Salud: Agencia administrativa y Organismo público de investigación. 1. Adecuación de la forma jurídica de Agencia administrativa. 2. Adecuación de la forma jurídica de Organismo público de investigación. VI. El peculiar proceso jurídico de creación del Instituto Andaluz de Salud y la difícil interpretación del nuevo artículo 52.bis LAJA. VII. El principio de instrumentalidad y las técnicas de tutela administrativa desplegadas sobre el Instituto Andaluz de Salud. VIII. Los fines encomendados al Instituto Andaluz de Salud y la atribución de potestades públicas y otras acciones para alcanzarlos. 1. La atribución genérica de potestades públicas. 2. ¿Cabe
\end{abstract}

* PGC 2018-093760-B-100 (Ministerio Ciencia, Innovación y Universidades, Fondos FEDER, "Seguridad Pública, Actividad Administrativa de Limitación y Derecho Sancionador").

Recibido: 11/01/2021

Aceptado: 30/04/2021 
atribuir potestad reglamentaria a una Agencia administrativa? 3. Otras acciones atribuidas al Instituto Andaluz de Salud y, en especial, la posibilidad de crear entes instrumentales propios. IX. Las especialidades del personal investigador y la compleja situación del personal al servicio del Instituto Andaluz de Salud. 1. La heterogénea composición del personal al servicio del Instituto Andaluz de Salud y su peculiar sistema de fuentes. 2. La integración del personal procedente de la Fundación Pública Andaluza Progreso y Salud y la Escuela Andaluza de Salud Pública, S.A. 3. La reserva del ejercicio de potestades públicas al personal funcionario. X. Conclusiones.

RESUMEN: Durante las tres últimas décadas, la Comunidad Autónoma de Andalucía ha desarrollado su propia política pública de I+D en materia sanitaria y de salud pública. Esta política pública, sin embargo, se ha hecho descansar fundamentalmente sobre entes privados instrumentales creados por la propia Administración y regidos por el Derecho Privado. Como resultado, esta política ha estado sometida a un régimen jurídico altamente disfuncional para los intereses públicos. Una reciente proposición de ley planteó la sustitución de estos entes instrumentales privados por una nueva Agencia administrativa de investigación sometida al Derecho Público. Aunque la proposición entró rápidamente en vía muerta, el presente trabajo analiza los principales cambios que proponía, sus fundamentos jurídicos y su posible impacto en la situación actual.

PALABRAS CLAVE: Administración pública andaluza, investigación sanitaria, organización administrativa, Agencia administrativa, Organismo público de investigación.

ABSTRACT: The Autonomous Community of Andalusia has carried out, during the last three decades, its own public policy in R\&D on public health and sanitary issues. However, this public policy has largely relied upon private legal persons, created by the Public Administration but subject to Private Law. As a result, this public policy has been ruled by a legal regime highly inconvenient for the public interest. A recent draft legislation proposed the substitution of those private legal persons by a new public research Agency subject to Public Law. This draft legislation was soon abandoned. Nevertheless, this paper analyses the main changes proposed therein, its legal grounds and their foreseeable impact in the current situation.

KEY WORDS: Andalusian public administration, healthcare research, administrative organization, Administrative agency, Public research organization. 


\section{INTRODUGGIÓN: UNA PROPOSICIÓN DE LEY PARA GREAR UN ORGANISMO PÚBLICO DE INVESTIGACIÓN EN MATERIA SANITARIA}

A comienzos de febrero de 2020 se publicaba en el Boletín Oficial del Parlamento de Andalucía una "Proposición de Ley relativa a creación del Instituto Andaluz de Salud" (sic), presentada apenas un mes antes por el Grupo Parlamentario Popular Andaluz1. El objetivo de la proposición, que aparentemente se enmarcaba en el proceso de racionalización del sector público andaluz, era la creación de un nuevo Organismo público de investigación (OPI) de la Junta de Andalucía (el segundo de su historia, tras el IFAPA $^{2}$ ), con naturaleza de Agencia administrativa, a partir de la transformación y fusión de dos entes de naturaleza privada del sector público andaluz: la Fundación Pública Andaluza Progreso y Salud y la Escuela Andaluza de Salud Pública, S.A. La creación de este Instituto Andaluz de Salud se completaría con la integración en su estructura orgánica y funcional de la actual Secretaría General de Investigación, Desarrollo e Innovación en Salud de la Consejería de Salud y Familias.

La creación del nuevo OPI por agregación de esos tres elementos no era descabellada. En efecto, la Fundación Pública Andaluza Progreso y Salud, la Escuela Andaluza de Salud Pública, S.A., y la Secretaría General de Investigación, Desarrollo e Innovación en Salud son agentes del Sistema Andaluz del Conocimiento, al ser entidades que intervienen "en los procesos de generación, transmisión, transformación y aprovechamiento del conocimiento". Igualmente, son agentes también del Sistema Sanitario Público de Andalucía (SSPA), en tanto que forman parte de los "recursos, medios organizativos y actuaciones de las Administraciones sanitarias públicas de la Comunidad Autónoma o vinculadas a las mismas, orientados a satisfacer el derecho a la protección de la salud"4. El nuevo Instituto Andaluz de Salud, por tanto, sería también un nuevo agente del Sistema Andaluz del Conocimiento y del Sistema Sanitario Público de Andalucía en el que se aglutinarían las estructuras especializadas en la investigación en salud.

1 Acuerdo de la Mesa de la Diputación Permanente del Parlamento de Andalucía de 29 de enero de 2020. Expediente 11-19/PPL-0000009, Boletín Oficial del Parlamento de Andalucía n. ${ }^{\circ}$ 258, de 4 de febrero de 2020, página 5. La proposición de ley había sido registrada por José Antonio Nieto Ballesteros, portavoz del G. P. Popular Andaluz, el 30 de diciembre de 2019. La Mesa de la Diputación Permanente, de acuerdo con lo dispuesto en el artículo 124.2 del Reglamento del Parlamento de Andalucía, acordó su publicación y su remisión al Consejo de Gobierno para que este manifestara su criterio respecto a su toma en consideración, así como su conformidad o no a la tramitación si implicara aumento de los créditos o disminución de los ingresos presupuestarios.

2 En rigor, el Instituto Andaluz de Investigación y Formación Agraria, Pesquera, Alimentaria y de la Producción Ecológica, creado por la Ley 1/2003, de 10 de abril.

3 Artículo 2.e) Ley 16/2007, de 3 de diciembre, Andaluza de la Ciencia y el Conocimiento.

4 Artículo 43 de la Ley 2/1998, de 15 de junio, de Salud de Andalucía. 
La iniciativa, sin embargo, generó un cierto revuelo en la Escuela Andaluza de Salud Pública, S.A., y en la ciudad de Granada, donde esta tiene su sede, puesto que se interpretó que la proposición de ley no tenía por objeto la transformación de dicho ente, sino su supresión o su traslado ${ }^{5}$. Como resultado, se sucedieron varias actuaciones políticas oponiéndose a la proposición, tanto en el Parlamento de Andalucía como, de manera un tanto desconcertante, en el Senado ${ }^{6}$. Todo ello, junto con alguna desavenencia interna en la coalición de gobierno, habría dado lugar a que la proposición se abandonase apenas unos días después?

5 Dieron noticia de ello varios diarios, tanto locales como nacionales: "PSOE e IU piden estabilidad en la EASP y Junta niega que la vaya a trasladar", La Vanguardia, 13/01/2020; R. ROMERO, Alba, "Nueva polémica por la absorción de la Escuela Andaluza de Salud Pública ubicada en Granada", Granada Hoy, 13/01/2020; VALLEJO, Susana, "El PSOE acusa a la Junta de «atentar» contra la seña de identidad de Granada con la nueva fusión en Salud. El grupo municipal asegura que es una decisión para «reforzar el eje Málaga-Sevilla» en contra de Granada", Granada Hoy, 13/01/2020; "La Junta asegura que la Escuela Andaluza de Salud Pública, con sede en Granada, no será trasladada a Sevilla ni cerrada", Ideal de Granada, 13/01/2020. Estas y otras muchas apariciones de este asunto en prensa se encuentran recogidas en un repositorio creado específicamente a tal efecto por el Comité de Empresa de la Escuela Andaluza de Salud Pública, S.A., en https://noalaextinciondelaeasp.org/actualidad/ .

6 Con fecha de 8 de junio de 2020, el Portavoz del Grupo Parlamentario Socialista, Ander Gil, y el senador por Granada Alejandro Zubeldia Santoyo, del mismo Grupo, presentaron una propuesta de Moción para que la Comisión de Sanidad y Consumo del Senado instara al Gobierno a que este solicitara a las instituciones andaluzas "Que se garantice que la EASP siga manteniendo su identidad, con las características normativas, orgánicas y funcionales actuales. El mantenimiento de la sede de la EASP en la ciudad de Granada" (sic). La Moción fue aprobada por la Comisión de Sanidad y Consumo del Senado en su sesión de 24 de noviembre de 2020 y la Mesa de la Cámara acordó, en su reunión del 14 de diciembre de 2020, tomar conocimiento de ella y comunicarla al Gobierno, de conformidad con el artículo 178.1 del Reglamento del Senado, ordenando su publicación en el Boletín Oficial de las Cortes Generales (BOCG. Senado, XIV Legislatura, n. ${ }^{\circ} 124$, de 17 de diciembre de 2020, p. 448).

7 Así cabría deducirlo de la aprobación, por parte del Pleno del Parlamento, en su sesión de 6 de febrero de 2020, con los votos a favor de los Grupos Socialista y Adelante Andalucía, el voto en contra del Grupo Vox en Andalucía y las abstenciones de los Grupos Popular Andaluz y Ciudadanos, de una "Proposición no de ley relativa a la defensa de la Escuela Andaluza de Salud Pública" (expediente 11-20/ PNLP-000006), del siguiente tenor:

"1. El Parlamento de Andalucía reconoce y considera imprescindible la labor que la Escuela Andaluza de Salud Pública, con sede en Granada, ha venido desarrollando desde su creación en 1985 en favor de la formación, cooperación internacional, investigación, innovación, consultoría nacional e internacional y su valiosa contribución al fortalecimiento del sistema sanitario público de Andalucía (SSPA) y de los sistemas sanitarios de España, Europa y América Latina. Por ello, el Parlamento de Andalucía declara que la EASP debe continuar tal como hoy está configurada, a todos los efectos, sin que deba modificarse su situación.

2. El Parlamento de Andalucía insta al Consejo de Gobierno a garantizar que la EASP siga manteniendo su identidad, con las características normativas, orgánicas y funcionales actuales.

3. El Parlamento de Andalucía insta al Consejo de Gobierno a garantizar que la sede de la EASP siga siendo la ciudad de Granada". 
Sin embargo, más allá de consideraciones políticas, lo cierto es que la proposición de ley de creación del Instituto Andaluz de Salud acertaba a señalar la caótica situación organizativa de la investigación sanitaria en Andalucía.

En efecto, durante varias décadas, el modelo organizativo de la Junta de Andalucía en este ámbito se ha basado en la acumulación de entes de naturaleza privada creados y sostenidos por la Administración pública andaluza. Este desarrollo orgánico, al menos en apariencia, no ha obedecido a ninguna planificación, sino a impulsos o necesidades políticas que, tal vez, no siempre han estado coordinados entre sí. Sin embargo, y a pesar de su naturaleza jurídica privada, estos entes han venido prestando verdaderos servicios públicos y actuando, de facto, como un elemento más de la Consejería de Salud, que se ha valido de ellos para desarrollar algunas de sus principales políticas públicas, en ocasiones con extraordinario éxito y reconocimiento, tanto nacional como internacional ${ }^{9}$. A pesar de ello, el régimen jurídico al que se encuentran sometidos no siempre ha resultado el más idóneo para las funciones que venían desarrollando o que se les han encomendado, lo que incluso ha dado lugar a un nutrido grupo de sentencias condenando a algunos de estos entes por prácticas ilegales ${ }^{10}$.

Frente a esta situación, la creación del Instituto Andaluz de Salud perseguía, por un lado, una reordenación y publificación de los principales entes instrumentales con que cuenta la Junta de Andalucía en materia de investigación en salud y, por otro, una simplificación del régimen jurídico al que se encuentran sometidos, adaptándolo al Derecho público y a la normativa vigente y estableciendo aquellas especialidades que puedan estar justificadas por la especificidad de sus funciones.

El objeto del presente trabajo, tomando como pretexto la indicada proposición de ley en la que se propuso la creación del Instituto Andaluz de Salud, es analizar la organización actual de la investigación sanitaria en la Administración de Andalucía,

$8 \quad$ No parece tratarse, por lo demás, de un fenómeno nuevo o extraño en la organización de la Junta de Andalucía, de la que se ha dicho que su criterio rector parece encontrarse "en el principio de descentralización funcional, solo que nunca se ha consagrado formalmente como un principio y es más bien el resultado, quizá no premeditado, de una multitud de decisiones inconexas", REBOLLO PUIG, M., "Los entes institucionales de la Junta de Andalucía y su utilización como medio propio", Revista de Administración Pública, no 161 (mayo - agosto 2003), p. 365.

9 De ello serían prueba, por ejemplo, los numerosos proyectos de investigación obtenidos en procesos de concurrencia competitiva nacionales e internacionales o, en el caso de la Escuela Andaluza de Salud Pública, S.A., su designación desde 2013, renovada en 2017, como Centro Colaborador de la Organización Mundial de la Salud en Servicios de Salud Integrados basados en la Atención Primaria.

10 Así ha ocurrido, destacadamente, con las numerosas condenas recaídas contra la Fundación Progreso y Salud por cesión ilegal de trabajadores y relacionadas con la puesta en práctica del "Plan integral Tabaquismo en Andalucía”, definitivamente confirmadas por la STS (Sala de lo Social) de 12 de febrero de 2020, n. ${ }^{\circ} 137 / 2020$ (ponente: Viroles Piñol). 
los principales problemas que presenta y las aparentes ventajas que podría tener una reorganización administrativa como la que se proponía.

\section{IDENTIFICACIÓN DE LOS ENTES A PARTIR DE LOS GUALES SE GREABA EL INSTITUTO ANDALUZ DE SALUD: LA FUNDA- GIÓN PÚBLICA ANDALUZA PROGRESO Y SALUD Y LA ESCUE- LA ANDALUZA DE SALUD PÚBLICA, SOGIEDAD ANÓNIMA}

La creación del Instituto Andaluz de Salud se planteaba como el resultado de la integración en un único ente con personalidad jurídica de los tres núcleos principales encargados hasta ahora, dentro de la Administración y el sector público andaluces, del desarrollo de las políticas de investigación sanitaria: la Fundación Pública Andaluza Progreso y Salud, la Escuela Andaluza de Salud Pública, S.A., y la Secretaría General de Investigación, Desarrollo e Innovación en Salud de la Consejería de Salud y Familias. Excedería del objeto de este trabajo realizar una exposición pormenorizada de la azarosa evolución de la Fundación Pública Andaluza Progreso y Salud y de la Escuela Andaluza de Salud Pública, S.A., a pesar de lo interesante e ilustrativo que ello resultaría, por cuanto ambas entidades ejemplifican de manera especialmente clara un criticable modelo de desarrollo de la Administración pública y la tantas veces denunciada "huida del Derecho Administrativo" (y huida de las garantías jurídicas) que lo ha caracterizado. En su lugar, basta ahora con indicar cuál es la situación jurídica y el contenido de las actividades de ambas entidades en la actualidad.

Aunque creada en 1996, la Fundación Pública Andaluza Progreso y Salud, en su composición actual, es el resultado de la fusión de tres Fundaciones públicas andaluzas previas, decidida mediante Acuerdo del Consejo de Gobierno de 11 de diciembre de 2012, en el marco de la Ley 1/2011, de 17 de febrero, de Reordenación del Sector Público de Andalucía ${ }^{11}$. Dicho acuerdo autorizó, al amparo del artículo 56 de la Ley 10/2005, de 31 de mayo, de Fundaciones de la Comunidad Autónoma de Andalucía, la fusión por absorción de la Fundación Pública Andaluza Progreso y Salud (ente absorbente), la Fundación Pública Andaluza para el Avance Tecnológico

11 Ampliamente sobre el profundo proceso de reforma en el que se enmarcó esta ley, ORTIZ MALLOL, J. "Una reforma del sector público de la Administración Andaluza: la vuelta al Derecho administrativo y la reducción del gasto público como principios inspiradores", RAAP, n. 79 (2011), pp. 257-288; FERNÁNDEZ RAMOS, S. "La reordenación del Sector Público Andaluz: Reflexiones para el debate", RAAP n. ${ }^{\circ} 80$ (2011), pp. 13-80; MONTOYA MARTÍN, E., "Reflexiones sobre el sector público instrumental en un contexto de crisis económica: la inaplazable hora de la racionalización”, en J. R. FUENTES I GASSÓ, J. GIFREU I FONT y L. CASADO CASADO (coords.), Estructuras administrativas y racionalización del gasto público. Problemas actuales de la expropiación forzosa. La reforma de los entes locales en Italia en el contexto de la crisis económica. Actas del VII Congreso de la Asociación Española de Profesores de Derecho Administrativo, INAP, Madrid, 2012, en especial, pp. 73-95; González Ríos, I., "Hacia una racionalización 'estructural' de los entes instrumentales: principios y reglas de inexcusable cumplimiento", RAAP, n. 88 (2014), en especial, pp. 44-54. 
y Entrenamiento Profesional (IAVANTE) y la Agencia de Calidad Sanitaria, Fundación Pública Andaluza (entes absorbidos), quedando estas dos últimas extinguidas. Del mismo modo, el citado Acuerdo del Consejo de Gobierno de 11 de diciembre de 2012 acordó también la modificación de los fines de la Fundación Pública Andaluza Progreso y Salud resultante, integrando los correspondientes a las dos fundaciones extinguidas.

En su versión actual, el artículo 5 de sus Estatutos (“Objeto de la Fundación”) establece que: "La Fundación tendrá por objeto, con carácter general, la realización de actividades que supongan un incremento en la salud de la población y una mejora en el funcionamiento de los servicios sociosanitarios, tales como planificación, organización, construcción, financiación, gestión y formación o cualesquiera otras que puedan ayudar a la consecución del objeto Fundacional (...)”. De conformidad con dicho objeto y con los fines recogidos en sus Estatutos, las principales actividades actualmente desarrolladas por la Fundación Pública Andaluza Progreso y Salud se centran:

- en la investigación e innovación en salud, gestionando convocatorias de ayudas financiadas con cargo al Presupuesto de la Comunidad Autónoma Andaluza y desarrollando investigaciones por sí misma a través de sus propios centros, todos ellos meras unidades organizativas sin personalidad jurídica, entre los que se encuentran RADyTTA (Red Andaluza de diseño y traslación de Terapias Avanzadas), CABIMER (Centro Andaluz de Biología Molecular y Medicina Regenerativa), GENYO (Centro Pfizer - Universidad de Granada - Junta de Andalucía de Genómica e Investigación Oncológica), BIONAND (Centro Andaluz de Nanomedicina y Biotecnología), etc. Asimismo, la Fundación Pública Andaluza Progreso y Salud coordina la llamada "Red de Fundaciones Gestoras de la Investigación del Sistema Sanitario Público de Andalucía (RFGI-SSPA)", en la que se agrupan otras cinco Fundaciones, de composición variada, cuya finalidad fundamental es dar cobertura a las actividades de investigación desarrolladas por el personal sanitario del Sistema Andaluz de Salud y sobre las que volveremos luego ${ }^{12}$;

- en la formación y evaluación de competencias profesionales en materia de salud, centrada fundamentalmente en el personal del Servicio Andaluz de Salud ${ }^{13}$;

12 Se trata de FISEVI (Fundación Pública Andaluza para la Gestión de la Investigación en Salud de Sevilla), FCÁDIZ (Fundación para la Gestión de la Investigación Biomédica de Cádiz), FABIS (Fundación Andaluza Beturia para la Investigación en Salud, radicada en Huelva), FIBICO (Fundación para la Investigación Biomédica de Córdoba), FIMABIS (Fundación Pública Andaluza para la Investigación de Málaga en Biomedicina y Salud) y FIBAO (Fundación para la Investigación Biosanitaria de Andalucía Oriental, que cubre las provincias de Granada, Jaén y Almería).

13 Estas actividades eran desarrolladas por la extinta Fundación Pública Andaluza IAVANTE, que aportó a la Fundación Progreso y Salud el Complejo Multifuncional Avanzado de Simulación e Innovación Tecnológica (CMAT), ubicado en el Parque Tecnológico de la Salud de Granada. Este último es gestionado, 
- en la certificación de la calidad de organizaciones sanitarias y de servicios sociales, sus profesionales, la formación que estos reciben y las páginas web de contenidos sanitarios, también centrada, fundamentalmente, en el Servicio Andaluz de Salud $^{14}$.

La mayor parte de las actividades indicadas (así como otras no mencionadas, como el desarrollo de infraestructuras TIC para el Sistema Sanitario Público de Andalucía) se orientan a satisfacer las necesidades de la Administración pública sanitaria andaluza y, muy especialmente, del Servicio Andaluz de Salud, sin perjuicio de que una parte de ellas puedan prestarse a terceras personas (cursos de formación externos, programas de asesoría, etc.). Cabe afirmar, por tanto, que la práctica totalidad de las actividades desarrolladas por la Fundación Pública Andaluza Progreso y Salud consisten en la prestación de servicios públicos en materia de salud correspondientes a la Administración de la Junta de Andalucía.

Por su parte, la veterana Escuela Andaluza de Salud Pública, S.A., cuya constitución fue autorizada por Acuerdo de Consejo de Gobierno de 2 de mayo de 1985, se creó marcando como objetivos prioritarios "la enseñanza, el asesoramiento y la investigación dirigidos a los profesionales y entidades relacionadas con la Salud Pública y Administración Sanitaria", lo que sigue constituyendo el núcleo básico de su objeto social ${ }^{15}$.

De manera coherente con dicho objeto social, aunque de forma tal vez contradictoria con los fines propios de una Sociedad Anónima, las principales actividades desarrolladas en la actualidad por la Escuela Andaluza de Salud Pública, S.A., consisten en:

- tareas de formación dirigidas a personal sanitario y de servicios sociales, procedente de manera casi exclusiva del Sistema Sanitario Público de Andalucía (SSPA)

a su vez, por la Fundación Pública Andaluza Parque Tecnológico de la Salud de Granada, actualmente adscrita a la Consejería de Transformación Económica, Industria, Conocimiento y Universidades, de conformidad con el artículo 2.4.ñ) del Decreto 117/2020, de 8 de septiembre, por el que se regula la estructura orgánica de esta Consejería.

14 Por su parte, estas actividades eran desarrolladas por la también extinta Agencia de Calidad Sanitaria de Andalucía, Fundación Pública Andaluza (ACSA). A pesar de que el término "agencia" pudiera inducir a error, la Fundación Progreso y Salud sigue manteniendo esta denominación para referirse a esta rama de su actividad, que constituye una mera unidad organizativa sin personalidad jurídica.

15 El artículo 2 ("Objeto social") de los Estatutos de la Escuela Andaluza de Salud Pública, Sociedad Anónima, cuya última modificación fue aprobada por Acuerdo de 6 de septiembre de 2016 de la Consejería de Salud (BOJA n. ${ }^{\circ}$ 174, de 9 de septiembre de 2016), dispone ahora que "La sociedad tiene como objeto social la generación de procesos de formación, asesoramiento, cooperación internacional, investigación y la creación de espacios de colaboración y redes que posibiliten la gestión del conocimiento, la salud pública y el buen gobierno de los sistemas de salud mediante: la formación (...), el asesoramiento (...), la investigación (...)". 
y del Sistema Público de Servicios Sociales de Andalucía (SPSSA), a las que cabe sumar las actividades del Centro Andaluz de Información y Documentación de Medicamentos-CADIME;

- tareas de consultoría en materia de Salud Pública y de Gestión de Servicios Sanitarios y Sociales, desarrolladas mayoritariamente por encargo de la Consejería de Salud y Familias y del Servicio Andaluz de Salud, pero también para empresas del ámbito sanitario, organismos internacionales, organizaciones públicas sanitarias y sociales y sociedades científicas y asociaciones;

- tareas de investigación, a través de sus propios grupos de investigación, en el campo de la epidemiología, la salud pública y los servicios sanitarios y sociales, así como a través del Registro de Cáncer de Granada, el Observatorio de la Infancia en Andalucía, el Observatorio de Prácticas Innovadoras en el Manejo de Enfermedades Crónicas Complejas - OPIMEC y el Observatorio de Salud y Medio Ambiente de Andalucía-OSMAN.

Tal y como ocurría con la Fundación Pública Andaluza Progreso y Salud, también en el caso de la Escuela Andaluza de Salud Pública, S.A., la mayor parte de sus actividades pretenden satisfacer necesidades de la Administración pública sanitaria de la Junta de Andalucía, sin perjuicio de que una parte de tales actividades se desarrolle, también, como prestación de servicios a terceros. Nuevamente cabe afirmar, por consiguiente, que la mayor parte de sus actividades consisten en la prestación de servicios públicos en materia de salud.

Finalmente, la creación del Instituto Andaluz de Salud se completaba con la integración en el nuevo ente de la Secretaría General de Investigación, Desarrollo e Innovación en Salud de la Consejería de Salud y Familias, entre cuyas funciones se incluyen, precisamente, "La dirección y ejecución de las políticas de investigación, desarrollo e innovación de la Consejería, así como las políticas de gestión del conocimiento", "La dirección, ejecución y evaluación de las políticas de acreditación y certificación de calidad" o "La planificación y coordinación de la formación de especialistas en ciencias de la salud en el Sistema Sanitario Público de Andalucía"16.

Atendiendo al contenido de estas y otras funciones, y a pesar de que la Fundación Pública Andaluza Progreso y Salud y la Escuela Andaluza de Salud Pública, S.A., están formalmente adscritas a la Viceconsejería ${ }^{17}$, su actividad se encuadra materialmente, en buena medida, en el ámbito propio de la Secretaría General de Investigación, Desarrollo e Innovación en Salud. Esta situación es la que explicaría

16 Cfr. artículos 2 y 5 del Decreto 105/2019, de 12 de febrero, por el que se establece la estructura orgánica de la Consejería de Salud y Familias y del Servicio Andaluz de Salud.

17 Cfr. artículos 2.3.b) y g) Decreto 105/2019, de 12 de febrero, por el que se establece la estructura orgánica de la Consejería de Salud y Familias y del Servicio Andaluz de Salud. 
que la creación del Instituto Andaluz de Salud contara también con la incorporación de este órgano de la Administración de la Junta de Andalucía como parte de su estructura orgánica, incorporación que podía verse también justificada por otras razones adicionales ${ }^{18}$.

\section{OTROS ENTES DELSEGTOR PÚBLICO ANDALUZDEDICADOS A LA INVESTIGACIÓN SANITARIA PERO NO INCLUIDOS EN EL PROCESO DE FUSIÓN Y TRANSFORMAGIÓN}

Según se ha indicado ya, la Fundación Pública Andaluza Progreso y Salud actúa como ente coordinador de la llamada "Red de Fundaciones Gestoras de la Investigación del Sistema Sanitario Público de Andalucía (RFGI-SSPA)". En dicha red, que se define a sí misma como un mero "espacio compartido de servicios", esto es, como una forma de colaboración no personificada, participan, además de la Fundación Pública Andaluza Progreso y Salud, las cinco Fundaciones antes indicadas:

- FISEVI, Fundación Pública Andaluza para la Gestión de la Investigación en Salud de Sevilla,

- FCÁDIZ Fundación para la Gestión de la Investigación Biomédica de Cádiz,

- FABIS, Fundación Andaluza Beturia para la Investigación en Salud (Huelva),

- FIBICO, Fundación para la Investigación Biomédica de Córdoba,

18 Por un lado, permitía dar cumplimiento al mandato contenido en el artículo 50.2 LAJA, conforme al cual, "Cuando se creen entidades instrumentales que supongan duplicación de la organización administrativa o de otras entidades ya existentes, habrán de suprimirse o reducirse debidamente las funciones o competencias de estas". Por otro lado, y desde una perspectiva más pragmática, la incorporación al Instituto Andaluz de Salud de los medios humanos de la Secretaría General de Investigación, Desarrollo e Innovación en Salud, permitía al nuevo ente contar desde el mismo momento de su creación con personal funcionario, imprescindible para poder ejercer buena parte de las potestades atribuidas por su ley de creación (artículo 9.2 TREBEP). Asimismo, este personal aportaba también la cultura organizativa, el modo de trabajar y el know-how propio de una Administración pública, lo que suponía un activo de extraordinario valor para una Agencia administrativa de nueva creación y conformada, en su mayor parte, por personal procedente de entidades privadas (por más que integradas en el sector público andaluz). No por casualidad, esta fue también la forma en que se actuó al crear el único precedente de Organismo Público de Investigación con forma de agencia administrativa que existe en Andalucía. En efecto, la creación del IFAPA conllevó la integración en su estructura orgánica y funcional de la entonces existente Dirección General de Investigación y Formación Agraria y Pesquera, de conformidad con la Disposición adicional segunda ("Adscripción de medios") de la Ley 1/2003, de 10 de abril, de creación del IFAPA. 
- FIMABIS, Fundación Pública Andaluza para la Investigación de Málaga en Biomedicina y Salud,

- FIBAO, Fundación Pública Andaluza para la Investigación Biosanitaria de Andalucía Oriental (Granada, Jaén y Almería).

Tres de estas fundaciones (FISEVI, FIMABIS y FIBAO) tienen la consideración de Fundaciones del Sector Público Andaluz y se encuentran adscritas a la Viceconsejería de Salud y Familias ${ }^{19}$. Atendiendo a ello, podría haberse planteado la conveniencia de que también estas fundaciones pudieran integrarse en el nuevo ente. Sin embargo, no es difícil adivinar algunas razones que habrían aconsejado rechazar esta posibilidad.

La más importante de ellas, seguramente, es que la fusión en el proyectado Instituto Andaluz de Salud de estas fundaciones y su consiguiente desaparición como personas jurídicas independientes afectaría al reconocimiento de los Institutos a los que dan soporte como "Institutos de Investigación Sanitaria" acreditados por el Instituto de Salud Carlos III. En efecto, la Comunidad Autónoma Andaluza cuenta actualmente con cuatro Institutos de Investigación Sanitaria acreditados, de acuerdo con el Real Decreto 279/2016, de 24 de junio, sobre acreditación de institutos de investigación biomédica o sanitaria, por el Instituto de Salud Carlos III ${ }^{20}$. Los cuatro institutos acreditados son:

- IBIS - Instituto de Biomedicina de Sevilla, acreditado el 25 de febrero de 2009, vinculado a FISEVI;

- IMIBIC - Instituto Maimónides de Investigación Biomédica de Córdoba, acreditado el 19 de septiembre de 2011, vinculado a FIBICO;

- IBIMA - Instituto de Investigación Biomédica de Málaga, acreditado el 15 de enero de 2015, vinculado a FIMABIS;

- ibs.Granada - Instituto de Investigación Biosanitaria de Granada, acreditado el 30 de noviembre de 2015, vinculado a FIBAO.

19 Artículos 2.3.c), d) y e) del Decreto 105/2019, de 12 de febrero, por el que se establece la estructura orgánica de la Consejería de Salud y Familias y del Servicio Andaluz de Salud.

20 Dicha acreditación constituye, en primer término, una típica medida de fomento de carácter honorífico. Como se indica en el preámbulo del Real Decreto, "la acreditación como IIS es un reconocimiento de la excelencia de los resultados científicos y de los retornos beneficiosos (sanitarios, sociales y económicos) producto de la labor investigadora en el entorno hospitalario". Junto con ello, la acreditación puede dar acceso a convocatoria específicas de ayudas gestionadas por el Instituto de Salud Carlos III. 
Estos Institutos de Investigación Sanitaria no tienen en sí mismos personalidad jurídica propia, sino que constituyen una forma de cooperación entre hospitales docentes y centros de $\mathrm{I}+\mathrm{D}+\mathrm{i}$. No deben confundirse con las Fundaciones que sí gozan de dicha personalidad y que les dan cobertura. De hecho, estas Fundaciones son uno de los elementos clave que se tienen en cuenta en el proceso de acreditación de los Institutos. En concreto, el artículo 4.a) del Real Decreto 279/2016, de 24 de junio, sobre acreditación de institutos de investigación biomédica o sanitaria, establece que, para otorgar la acreditación como Instituto de Investigación Sanitaria, será necesario que las entidades solicitantes justifiquen la concurrencia de un listado de requisitos, entre los que se señala la existencia de una entidad con personalidad jurídica propia a quien se atribuya la representación del Instituto ${ }^{21}$.

De esta forma, las Fundaciones vinculadas al IBIS (Instituto de Biomedicina de Sevilla), al IBIMA (Instituto de Investigación Biomédica de Málaga) y al ibs.Granada (Instituto de Investigación Biosanitaria de Granada), es decir, las Fundaciones FISEVI (Fundación Pública Andaluza para la Gestión de la Investigación en Salud de Sevilla), FIMABIS (Fundación Pública Andaluza para la Investigación de Málaga en Biomedicina y Salud) y FIBAO (Fundación para la Investigación Biosanitaria de Andalucía Oriental), serían las entidades con personalidad jurídica propia vinculadas al Instituto que permiten cumplir el requisito indicado.

La supresión de estas Fundaciones conllevaría, por lo tanto, el incumplimiento de dicho requisito y, consecuentemente, la pérdida de la acreditación como Institutos de Investigación Sanitaria de los cuatros institutos andaluces actualmente acreditados. La forma de evitar esto pasaba, justamente, por mantener la personalidad jurídica diferenciada de estas Fundaciones, que pasaban a quedar adscritas al Instituto Andaluz de Salud, de acuerdo con el artículo 9.2 de la proposición.

Y todo ello sin perjuicio de que, como parecía prefigurarse en la proposición de ley, tales Fundaciones (así como las otras incluidas en la "Red de Fundaciones Gestoras de la Investigación del Sistema Sanitario Público de Andalucía”), pudieran ser transformadas en consorcios, en el sentido de lo previsto en el artículo 12 LAJA, de los que formaría parte el Instituto Andaluz de Salud ${ }^{22}$.

21 En concreto, el artículo 4.a) del Real Decreto 279/2016 exige la acreditación de "a) Un instrumento jurídico que ampare la asociación de los hospitales docentes del SNS con los centros públicos o privados de $\mathrm{I}+\mathrm{D}+\mathrm{i}$ que han de integrar los IIS. Se considera instrumento jurídico suficiente la formalización de convenios de colaboración que, como contenido mínimo, identifiquen los compromisos asumidos por cada una de las partes, atribuyan la representación de los IIS a entidades con personalidad jurídica propia vinculadas al IIS, e incorporen la creación de un órgano colegiado de gobierno del IIS que deberá contar con la representación de todas las entidades que se asocien para formar el IIS (...)".

22 Como se ha indicado más atrás, todas estas fundaciones son una forma orgánica de participación de una pluralidad de entidades entre las que se incluye a la Administración de la Junta de Andalucía. Ello significa que están configuradas de facto como una forma de "organizaciones personificadas de gestión" 


\section{LA INADEGUAGIÓN DE LAS FORMAS JURÍDICAS PRIVADAS PARA LA PRESTACIÓN DE LOS SERVICIOS PÚBLICOS ASIG- NADOS A LA FUNDACIÓN PÚBLICA ANDALUZA PROGRESO Y SALUD Y LA ESCUELA ANDALUZA DE SALUD PÚBLICA, S.A.}

La utilización de formas jurídicas privadas (como la de fundación o, muy especialmente, la de sociedad mercantil) parece especialmente indicada cuando lo que se busca es que el ente actúe en un entorno privado, que sea autosuficiente desde un punto de vista financiero y que, para ello, se rija por criterios de racionalidad económica. Es decir, que oriente su actividad de acuerdo con lo que puede resultar más provechoso desde un punto de vista económico. Sin embargo, cuando el fin que se persigue es la satisfacción de intereses públicos y lo que se pretende es someter la actividad del ente a criterios de eficiencia social y no solo de eficiencia económica, la forma jurídica más apropiada es la pública.

Aunque no sería difícil especular con ello, lo cierto es que no se conocen los motivos por los que la Administración de la Junta de Andalucía decidió, en su momento, que la mejor forma de prestar los servicios públicos que, de hecho, vienen prestando la Fundación Pública Andaluza Progreso y Salud y la Escuela Andaluza de Salud Pública, S.A, era mediante personificaciones jurídicas privadas sometidas al Derecho privado. En sentido contrario, sí que resulta posible señalar un buen número de razones que permiten afirmar la inadecuación de estas formas jurídicas a los fines a los que deben servir.

Fundamentalmente, las formas jurídicas privadas empleadas por la Fundación Pública Andaluza Progreso y Salud y la Escuela Andaluza de Salud Pública, S.A., implican renunciar al régimen jurídico que resulta más idóneo para la protección de los intereses generales y que se vincula al ejercicio de los privilegios y potestades exorbitantes propios de las Administraciones públicas ${ }^{23}$. Esta renuncia conlleva aceptar

en el sentido de las reguladas en el artículo 12 LAJA. Es decir, funcionan como un mecanismo para que la Administración de la Junta de Andalucía y otras entidades públicas o privadas persigan la consecución de finalidades de interés común mediante la creación, de común acuerdo, de una persona jurídica encargada de ello. El artículo 12 LAJA, en su redacción actual, parece rechazar, sin embargo y con buen criterio, que estas "organizaciones personificadas de gestión" puedan adoptar la forma de fundaciones, optando en su lugar por la forma de consorcios o de sociedades mercantiles. De conformidad con ello, estas fundaciones públicas podían haberse adaptado a formas consorciadas que, en su caso, podrían haberse adscrito al Instituto Andaluz de Salud, tal y como parecía prefigurarse en los artículos 8.1 y 9.2 de la proposición de ley. Este es, por lo demás, el mismo modelo seguido por el Instituto de Salud Carlos III, que distingue entre centros propios (unidades y estructuras sin personalidad jurídica, pero con una amplia autonomía científica y funcional) y otros centros que sí gozan de personalidad jurídica y que adoptan la forma de consorcio cuando son el cauce de participación de otros entes ajenos al Instituto (v. gr., los conocidos como CIBER o Consorcio Centro de Investigación Biomédica en Red).

23 Cfr. artículos 52 y 75 LAJA y artículo 57.1 Ley 10/2005, de 1 de mayo, de Fundaciones de la Comunidad Autónoma de Andalucía. 
un coste de oportunidad y asumir un riesgo de desprotección que de ninguna forma puede quedar compensado con las ventajas, reales o imaginarias, que las formas de gestión privada pueden aportar ${ }^{24}$.

En primer lugar, se produce una ausencia casi total de garantías para los ciudadanos y para los propios empleados de estos entes frente a los servicios públicos de los que son usuarios y frente al resto de su actuación. Por ejemplo, a pesar de tramitar verdaderos procedimientos (de evaluación, de acreditación, de subvenciones, de contratación de personal, etc.) no se reconocen a los ciudadanos los derechos propios del procedimiento administrativo: derecho de acceso al expediente, a conocer el estado de la tramitación, a conocer al personal que participa en el procedimiento, a obtener orientación, a ser requerido para subsanar, etc. No cuentan con registros administrativos. No están sometidos a reglas sobre el deber de resolver, sobre el plazo máximo para tramitar los procedimientos, sobre la producción del silencio, etc. No hay reglas sobre el cómputo de plazos. No hay reglas sobre el modo en que deben ejercerse las competencias, es decir, reglas que permitan determinar quiénes son los órganos competentes para actuar en cada momento, normas que regulen el funcionamiento de los órganos colegiados o que fijen las causas de abstención y recusación que garanticen la imparcialidad en la adopción de decisiones. De hecho, estos entes tampoco cuentan con reglas sobre la producción de decisiones (la forma que deben adoptar, su contenido mínimo, la exigencia de motivación, el modo en que deben ser notificadas, etc.). Finalmente, tampoco existe posibilidad de solicitar la revisión de oficio de las propias decisiones, ni de interponer recursos administrativos ante los órganos superiores o ante los órganos de la Consejería, lo que obliga a los ciudadanos, en caso de discrepancia, a acudir a los órganos judiciales, que, por lo demás, no serán los órganos del orden jurisdiccional contencioso-administrativo, sino los del orden jurisdiccional civil.

En segundo lugar, estos entes carecen de todos los privilegios de los que habitualmente gozan las Administraciones públicas en sus relaciones con la Administración de Justicia: sus actos carecen de presunción de validez, de ejecutividad y de ejecutoriedad, lo que impide que puedan ser objeto de ejecución forzosa (dificultando, por ejemplo, la recuperación de sumas de dinero o el cobro de créditos); carecen de privilegios extraprocesales, lo que les obliga a actuar ante la vía judicial correspondiente en lugar de estar amparados por el carácter revisor propio del contencioso-ad-

24 Precisamente por ello, la más reciente doctrina aboga por extender también a estas entidades del sector público con personalidad de Derecho privado que ejercen potestades administrativas la aplicación de las normas de Derecho Administrativo. Sobre todo ello, con muy fundamentadas razones (aunque con complejas consecuencias), GAMERO CASADO, E., "Ejercicio de potestades administrativas por entidades del sector público con personalidad de Derecho privado", en E. GAMERO CASADO (dir.), La potestad administrativa, Tirant lo Blanch, Valencia, 2021, pp. 388-450. 
ministrativo; carecen, igualmente, de privilegios procesales: no reciben asistencia jurídica del Gabinete Jurídico de la Junta (salvo convenio expreso, ex artículo 41.3 LAJA), deben prestar caución en el seno de los procedimientos judiciales; etc.

En tercer lugar, al tratarse de entes de naturaleza privada, todas sus relaciones laborales se rigen por el Derecho laboral, lo que genera nuevos inconvenientes: no queda garantizada la inamovilidad de sus empleados, pieza clave para la independencia de los empleados públicos en sus actuaciones; no puede aplicarse el régimen disciplinario de los empleados públicos, sino el mucho más liviano de los trabajadores privados, lo que puede dar lugar a que ciertas conductas, cuya comisión por un empleado público repugnan a la conciencia social, queden impunes (v.gr., no respetar los derechos fundamentales de los ciudadanos); y, lo que resulta seguramente más grave, únicamente hay una aplicación muy parcial de los principios de publicidad, igualdad, mérito y capacidad ${ }^{25}$.

En cuarto lugar, en relación con las actividades de la Fundación Pública Andaluza Progreso y Salud como ente concedente de ayudas a la investigación, es preciso subrayar que estas no pueden tener, por definición, la consideración de subvenciones, debiendo tratarse como meras donaciones civile ${ }^{26}$. Ello genera, nuevamente, todo tipo de inconvenientes para la mejor protección de los intereses generales. Así, no hay garantías en el procedimiento de concesión (igualdad, transparencia, motivación, posibilidad de presentar alegaciones, posibilidad de interponer recursos); no existen controles sobre los beneficiarios, al no tener acceso a la Base de Datos Nacional de Subvenciones; no es posible desplegar las potestades de inspección propias de la Administración concedente o de la Intervención General de la Junta de Andalucía; en caso de incumplimiento, resulta imposible acordar el reintegro y solo cabe intentar revocar la subvención por incumplimiento modal, solicitando a los jueces de lo civil que así lo declaren; resulta igualmente imposible que la Fundación pueda recuperar el dinero coactivamente por sí misma, debiendo acudir nuevamente, a los órganos judiciales civiles; finalmente, tampoco cabe imponer sanciones a los beneficiarios incumplidores (por ejemplo, para evitar que un beneficiario infractor reciba ayudas de otras convocatorias).

25 Así lo detectó, de hecho, la Cámara de Cuentas de Andalucía al fiscalizar a la Escuela Andaluza de Salud Pública, S.A., y a la Fundación Pública Andaluza Progreso y Salud. Cfr. la conclusión 131 del Informe de Fiscalización de Regularidad de la Escuela Andaluza de Salud Pública, S.A. (OE 06/2011), correspondiente al ejercicio 2010, último del que se tiene constancia, en la que se constató que no estaba acreditada la publicidad de los procesos de reclutamiento y selección. La misma situación fue detectada en relación con al menos dos procesos selectivos de la Fundación Pública Andaluza Progreso y Salud, según recogió el Informe de Fiscalización de Regularidad de la Fundación Progreso y Salud (OE 03/2011), ap. 31.

26 Cfr., sin embargo, la perturbadora redacción dada a la Disposición adicional decimosexta de la Ley General de Subvenciones por la disposición final 7.2 de la Ley 40/2015, de 1 de octubre, de Régimen Jurídico del Sector Público. 
En quinto lugar, el patrimonio de la Escuela Andaluza de Salud Pública, S.A., y de la Fundación Pública Andaluza Progreso y Salud es un patrimonio estrictamente privado, sometido al Derecho Civil, sin que resulte posible extenderle el régimen jurídico de los bienes públicos, a pesar de resultar mucho más garantista para los bienes que permiten prestar servicios públicos. Así, sus bienes no pueden incluirse en la categoría de bienes demaniales y, en consecuencia, no pueden gozar de las ventajas de la inalienalibilidad, la imprescriptibilidad o la inembargabilidad; no existe obligación de mantener un registro con el inventario de bienes, indicando su ubicación y el etiquetado de los bienes (lo que determina la imposibilidad de conciliaciones periódicas, como también ha denunciado en alguna ocasión la Cámara de Cuentas de Andalucía ${ }^{27}$ ); no pueden ejercerse las potestades de conservación de la Administración (recuperación posesoria, deslinde, desahucio administrativo, investigación); tampoco puede aplicarse el régimen sancionador propio de los bienes públicos para protegerlos. La desprotección de sus bienes resulta especialmente difícil de aceptar si se atiende a que, muchos de ellos, fueron financiados mediante dinero público ${ }^{28}$.

\section{LA ADEGUACIÓN DE LAS FORMAS JURÍDICAS PROPUESTAS PARA EL INSTITUTO ANDALUZ DE SALUD: AGENCIA ADMI- NISTRATIVA Y ORGANISMO PÚBLICO DE INVESTIGACIÓN}

\section{Adecuación de la forma jurídica de Agencia administrativa}

Frente a la inconveniencia del uso de formas jurídicas privadas para la gestión de los servicios públicos que la Fundación Pública Andaluza Progreso y Salud y la Escuela Andaluza de Salud Pública, S.A., vienen prestando, la configuración del proyectado Instituto Andaluz de Salud como una Agencia administrativa y como un Organismo público de investigación resultaba, seguramente, mucho más razonable.

27 Se trataría, además, de un problema común a ambos entes, puesto de manifiesto por los Informes de Fiscalización de Regularidad realizados por la Cámara de Cuentas de Andalucía tanto en relación con la Fundación Pública Andaluza Progreso y Salud (OE 03/2011), ap. 25, como con la Escuela Andaluza de Salud Pública, S. A. (OE 06/2011), aps. 28-30.

28 A mero título de ejemplo, cabe señalar las importantísimas subvenciones concedidas a la Fundación Pública Andaluza Progreso y Salud con el fin de poner en marcha su Centro Andaluz de Biología Molecular Regenerativa y el Banco de Líneas Celulares. Solo con cargo al Presupuesto de la Junta de Andalucía para 2006 se concedieron subvenciones por valor de casi diez millones de euros, que se verían aumentadas en años posteriores: Orden de la Consejería de Salud de 24 de abril de 2007, por la que se hace pública la relación de subvenciones que se citan (BOJA n. ${ }^{\circ}$ 92, de 10 de mayo 2007); Resolución de 13 de diciembre de 2006, de la Secretaría General de Universidades, Investigación y Tecnología, por la que se acuerda la publicación de subvenciones excepcionales concedidas por la Consejería de Innovación, Ciencia y Empresa (BOJA n. ${ }^{\circ}$ 10, de 15 de enero 2007); Resolución de 16 de enero de 2007, de la Secretaría General de Universidades, Investigación y Tecnología, por la que se acuerda la publicación de subvenciones excepcionales concedidas por la Consejería de Innovación, Ciencia y Empresa (BOJA n. ${ }^{\text {35, de }} 16$ de febrero 2007). 
Debe partirse de la constatación de un hecho ya enunciado: las actividades que desarrollan mayoritariamente los entes que se proponía suprimir constituyen servicios públicos típicos. Más en concreto, se trata de actividades típicamente desarrolladas por Organismos públicos de investigación, por centros educativos o por servicios similares de atención a la ciudadanía general o de asesoramiento a los poderes públicos integrados en la Administración. Dicho de otra forma: la experiencia muestra que la prestación de estos servicios puede y, de hecho, suele hacerse con toda normalidad a través de formas jurídicas plenamente sometidas al Derecho Administrativo. De hecho, podrían pasar a ser prestados directamente por la Administración general de la Junta de Andalucía.

No obstante, el altísimo grado de especialización técnica y científica de las actividades que deben llevarse a cabo justificarían que, por razones de eficacia, se pudiera contar con una organización que gozara de una cierta autonomía de gestión (artículo 50.1 LAJA), lo que podría justificar la existencia de entidades instrumentales de la Administración de la Junta de Andalucía en este ámbito. Cuestión distinta es la naturaleza y el régimen jurídico que tales entidades instrumentales deberían tener.

Precisamente porque las funciones que debía desarrollar el proyectado Instituto Andaluz de Salud eran las propias de una Administración general, es por lo que la forma jurídica más apropiada para el nuevo ente parecía ser, efectivamente, la de Agencia administrativa, esto es, las agencias previstas y reguladas en los artículos 65-67 LAJA. Tal ha sido, por lo demás, la opción escogida por los principales Organismos públicos de investigación de ámbito estatal en España (el Instituto de Salud Carlos III, precisamente en materia de salud, y el Centro Superior de Investigaciones Científicas). Y fue también la opción seguida en la Junta de Andalucía con el único Organismo público de investigación con el que cuenta su Administración, el IFAPA ${ }^{29}$.

Las ventajas que, en la práctica, aportaba esta solución, eran justamente el reverso de todos los inconvenientes a los que deben enfrentarse la Fundación Pública Andaluza Progreso y Salud y la Escuela Andaluza de Salud Pública, S.A., y que hemos enumerado en el epígrafe anterior. En concreto, la naturaleza de Agencia administrativa del Instituto Andaluz de Salud permitía, entre otras ventajas, aplicar todas las garantías para los ciudadanos propias del procedimiento administrativo, beneficiarlo con los privilegios propios de las Administraciones públicas en su relación con la Administración de Justicia, someter sus relaciones laborales al régimen de los empleados públicos, aplicar la normativa propia de las subvenciones públicas en

29 Cfr. artículo 1 Ley 1/2003, de creación del IFAPA, que lo configuró como "organismo autónomo (...) conforme a lo previsto en el artículo 4.1 a) de la Ley 5/1983, de 19 de julio, General de la Hacienda Pública de la Comunidad Autónoma de Andalucía", lo que constituía el antecedente inmediato de las Agencias administrativas andaluzas. 
sus procedimientos de concesión de ayudas, proteger sus bienes mediante la normativa de bienes públicos, etc. En definitiva, el Instituto Andaluz de Salud podría ejercer verdaderas potestades públicas, quedando plenamente sometido a los mecanismos garantistas propios del Derecho público ${ }^{30}$.

Tal era el régimen que mejor se adaptaba a la prestación de servicios públicos que se le encomendaba, sin que ello obstase a que algunas de sus actividades pudieran prestarse como servicios a terceros en el mercado, tal y como vienen siendo prestados ahora mismo por la Fundación Pública Andaluza Progreso y Salud y por la Escuela Andaluza de Salud Pública, S.A. Cabe aclarar que, lejos de suponer una anomalía, este tipo de prestaciones constituyen actuaciones absolutamente normales en la actividad ordinaria de los Organismos públicos de investigación (o, por usar un ejemplo cercano, de las Universidades públicas), previstas normativamente y reguladas habitualmente como "transferencia de resultados de la investigación". De hecho, lo habitual es que los Organismos públicos de investigación (y las Universidades públicas) cuenten con una Oficina de Transferencia de Resultados de la Investigación (OTRI) encargada de tramitar los contratos que permiten la prestación de sus servicios $^{31}$.

Por otro lado, el carácter marginal de este tipo de prestaciones, meramente complementarias de las que se dibujaban como principales funciones del Instituto Andaluz de Salud como proveedor de servicios al Sistema Sanitario Público Andaluz, excluían que debiera optarse por otras formas jurídico-públicas, como las Agencias públicas empresariales (artículos 68-70 LAJA), caracterizadas por aplicar "técnicas de gestión empresarial en ejecución de competencias propias o de programas específicos de una o varias Consejerías, en el marco de la planificación y dirección de estas". Y tampoco parecía justificada la creación del Instituto Andaluz de Salud como Agencia de régimen especial (artículos 71-74 LAJA), pues este tipo de entes se definen como Agencias administrativas a las que se les asignan "funciones que impliquen ejercicio de autoridad que requieran especialidades en su régimen jurídico" (artículo 71 LAJA), lo que no parecía concurrir en este caso.

30 En ese sentido, el artículo 5.2 de la proposición de ley, sobre el que volveremos más adelante, establecía que el Instituto Andaluz de Salud gozaría "de todas las prerrogativas atribuidas por el ordenamiento a las Administraciones públicas y dispondrá de todas las potestades públicas precisas, salvo la expropiatoria”.

31 En relación con estos órganos, vid., recientemente, CABALLERO LOZANO, J. M., "Intermediación en la transferencia de los resultados de investigación a la sociedad: estudio de las oficinas de transferencia de los resultados de investigación y otras entidades mediadoras", en R. de ROMÁN PÉREZ (coord.), La propiedad intelectual en las universidades públicas: titularidad, gestión y transferencia, Comares, Granada, 2016, pp. 305-324. 


\section{Adecuación de la forma jurídica de Organismo público de investigación}

Además de concederle una amplia autonomía de administración y gestión, la proposición de ley de creación del Instituto Andaluz de Salud marcaba muy fuertemente su naturaleza de ente científico e investigador de carácter público. Así cabía apreciarlo en muchos de sus preceptos y, con especial claridad, en su artículo 13.2, en el que se establecían unos inusuales requisitos para poder ocupar la Dirección del Instituto, máximo órgano unipersonal del ente. De conformidad con este precepto, la persona que ocupara la Dirección no solo debía ser elegida entre funcionarios de carrera, sino que, además, debía estar en posesión del título de doctor.

La primera de las exigencias, muy excepcional en los órganos superiores y directivos de la Administración de la Junta de Andalucía y de sus entidades instrumentales $^{32}$, podría interpretarse como un mecanismo de mejora interna de la Administración, en la medida en que suponía una garantía tendencial de la profesionalidad de la persona elegida y, muy especialmente, de sus conocimientos acerca del funcionamiento de la Administración pública ${ }^{33}$. En el caso específico del Instituto Andaluz de Salud, ciertamente podía resultar una temeridad que se pusiera a su frente a una persona que, aun contando con amplios conocimientos científicos y técnicos en materia sanitaria o de salud pública, no tuviera, igualmente, un conocimiento suficiente de la Administración pública, sus reglas internas de gestión y funcionamiento o de las normas que le resultan de aplicación (en materia de contratación, empleo público, gestión presupuestaria, etc.). En efecto, son conocidos los casos en los que se han producido "fichajes estrella" de muy reconocidos expertos del sector privado, con amplia experiencia y sobrado prestigio en el ámbito de la investigación y la ciencia, para gestionar organismos o programas públicos y que han acabado en situaciones de fracaso colectivo y profunda frustración, por no entender las exigencias a las que estaba sometida su actividad cuando se desempeña en el ámbito público.

La segunda de las exigencias, estar en posesión del grado de doctor, constituía una absoluta novedad, al menos hasta donde conocemos, como requisito de nombramiento para un alto cargo de la Administración andaluza (o española). Sin embargo, las muy especiales características de la actividad científica posiblemente justificaban con creces esta exigencia, que vendría a complementar a la anterior. En efecto, os-

32 En principio, a diferencia de lo que ocurre en la Administración General del Estado, solo se exige la condición de funcionario a las personas titulares de las Secretarías Generales Técnicas, de la Secretaría General competente en materia de Administración Pública, de las Direcciones Generales que tengan competencias en materia de Administración Pública, de la Intervención General de la Junta de Andalucía y de la Dirección de la Agencia Tributaria de Andalucía (artículo 17.5.2 LAJA).

33 Ello explicaría que el mismo requisito fuera exigido también por el artículo 18.1 de la proposición para el nombramiento del Secretario General del Instituto, cuyas funciones parecían equipararse a las de un Secretario General Técnico. 
tentar la condición de personal funcionario, incluso en cuerpos en los que se exija el nivel de licenciatura o grado, y tener, por tanto, un conocimiento suficiente de la Administración pública no habilita por sí mismo para entender el funcionamiento y la dinámica de la actividad científica. A diferencia de otras actividades, el correcto desarrollo y la gestión de la actividad científica y, en especial, de la actividad científica de máximo nivel, exige poseer ciertas competencias que únicamente ostentan aquellas personas integradas en esta comunidad epistémica, es decir, quienes se dedican a la ciencia ${ }^{34}$.

De manera coherente con este carácter de ente público científico e investigador con el que se le pretendía dotar, además de configurarlo como Agencia administrativa, la proposición de ley de creación del Instituto Andaluz de Salud también le atribuía naturaleza de Organismo público de investigación (OPI). Para entender qué implica dicha naturaleza es necesario acudir al concepto de OPI acuñado en el artículo 47.1 Ley 14/2011, de 1 de junio, de la Ciencia, la Tecnología y la Innovación (Ley de la Ciencia), conforme al cual: "Son Organismos Públicos de Investigación los creados para la ejecución directa de actividades de investigación científica y técnica, de actividades de prestación de servicios tecnológicos, y de aquellas otras actividades de carácter complementario, necesarias para el adecuado progreso científico y tecnológico de la sociedad, que les sean atribuidas por esta ley o por sus normas de creación y funcionamiento (...)".

La calificación como OPI no es meramente anecdótica o circunstancial. Antes al contrario, el ser clasificado dentro de esta categoría permite acceder a ciertos regímenes jurídicos especiales, fundamentalmente en materia de convenios, de patentes, de contratación pública o de contratación de personal, en los términos previstos en la propia Ley de la Ciencia, el TREBEP, el Estatuto de los Trabajadores o la Ley 9/2017, de 8 de noviembre, de Contratos del Sector Público (téngase en cuenta, en especial, su "Disposición adicional quincuagésima cuarta. Régimen aplicable a los contratos celebrados por los agentes públicos del Sistema Español de Ciencia, Tecnología e Innovación”) y en alguna otra normativa. En efecto, las consecuencias de que un ente sea calificado como Organismo público de investigación se derivan de otras muchas normas de nuestro ordenamiento, dando lugar a un régimen jurídico ciertamente disperso y, por ello mismo, justamente criticado por la doctrina ${ }^{35}$.

34 Asimismo, esta exigencia resultaba también coherente con el hecho de que el cuerpo de personal investigador funcionario que pretendía crear expresamente para el Instituto Andaluz de Salud la proposición de ley (artículo 28.1) estableciera como requisito de acceso estar en posesión del grado de doctor. Podía entenderse, pues, razonable, que la persona que ejerciera la jefatura superior sobre todas ellas debiera serlo también.

35 Entre las críticas más recientes, CUETO PÉREZ, M., "Necesidad de una nueva configuración de los Organismos públicos estatales de investigación", Revista General de Derecho Administrativo n. 51 (2019), pp. 1-32. 
Por ejemplo, la configuración como Organismo público de investigación del Instituto Andaluz de Salud le habría permitido reforzar algunas de las capacidades docentes desarrolladas por la Fundación Pública Andaluza Progreso y Salud o la Escuela Andaluza de Administración Pública, S.A. Así, le habría permitido beneficiarse del régimen especial de citas y reseñas e ilustración con fines educativos o de investigación científica regulado en el artículo 32 del Texto Refundido de la Ley de Propiedad Intelectual, aprobado por Real Decreto Legislativo 1/1996, de 12 de abril, y que se encuentra reservado "[a]l profesorado de la educación reglada impartida en centros integrados en el sistema educativo español y el personal de Universidades y Organismos públicos de investigación en sus funciones de investigación científica".

La consideración de Organismo público de investigación también habría conllevado algunas ventajas fiscales. En concreto, el Texto Refundido de la Ley Reguladora de las Haciendas Locales aprobado por Real Decreto Legislativo 2/2004, de 5 de marzo, prevé:

- en su artículo 74.2.bis, que "Los ayuntamientos mediante ordenanza podrán regular una bonificación de hasta el 95 por ciento de la cuota íntegra del impuesto a favor de inmuebles de Organismos públicos de investigación y los de enseñanza universitaria";

- en su artículo 82.1.e), la exención de Impuesto sobre Actividades Económicas a los Organismos públicos de investigación.

Del mismo modo, en tanto que Organismo público de investigación el Instituto Andaluz de Salud también habría podido constituir empresas innovadoras de base tecnológica, de acuerdo con lo previsto en el artículo 56.1 de la Ley 2/2011, de 4 de marzo, de Economía Sostenible.

Finalmente, la configuración como Organismo público de investigación habría supuesto una importante mejora de la relación de los entes objeto de transformación y fusión con las Universidades. En particular, y de conformidad con lo dispuesto en la Ley Orgánica 6/2001, de 21 de diciembre, de Universidades (LOU):

- el Instituto Andaluz de Salud podría haber creado Institutos Mixtos de Investigación, junto con Universidades públicas, de los regulados en el artículo 10.2.2 $2^{\circ} \mathrm{LOU}$;

- también podría haber creado o financiado escuelas de doctorado en colaboración con una Universidad, de acuerdo con el artículo 30.ter LOU; 
- su personal investigador en posesión del Título de doctor podría haber realizado funciones de dirección de tesis doctorales, previo acuerdo del órgano responsable del programa de doctorado de la respectiva Universidad, tal y como establece la sección III ("Funciones de dirección de tesis doctorales”) del capítulo I del título IX LOU;

- y el personal perteneciente a los cuerpos docentes universitarios podría haber ocupado puestos de trabajo adscritos al Instituto Andaluz de Salud para realizar labores relacionadas con la investigación científica y técnica, mediante los mecanismos de movilidad previstos en la normativa de función pública, de conformidad con la Disposición adicional décima LOU.

Todo lo anterior, en suma, parecía justificar sobradamente la conveniencia de calificar al Instituto Andaluz de Salud como Organismo público de investigación, figura sorprendentemente poco utilizada hasta la fecha por la Administración andaluza $^{36}$.

\section{EL PECULIAR PROCESO JURÍDICO DE GREACIÓN DEL INSTITUTO ANDALUZ DE SALUD Y LA DIFÍCIL INTERPRE- TACIÓN DEL NUEVO ARTÍCULO 52.BIS LAJA}

La creación del Instituto Andaluz de Salud, acordada en el artículo 2 de la proposición, implicaba tres operaciones que se realizaban simultáneamente. En primer lugar, la transformación de dos entes del sector público andaluz con naturaleza de fundación pública (Fundación Pública Andaluza Progreso y Salud) y de sociedad mercantil (Escuela Andaluza de Salud Pública, S.A.), en Agencias administrativas; en segundo lugar, la fusión de ambas agencias en una sola; en tercer lugar, la integración, como parte del nuevo ente, de los órganos y unidades administrativas que actualmente conforman la Secretaría General de Investigación, Desarrollo e Innovación en Salud.

Al realizarse toda la operación en unidad de acto por ministerio de la ley, resultaba posible acordar, en línea con lo previsto en el artículo 52.bis.2 LAJA, la cesión e integración global de todo el activo y el pasivo de las entidades transformadas y la sucesión universal en todos sus derechos y obligaciones ${ }^{37}$. Como consecuencia y principal ventaja de todo ello, las dos entidades objeto de transformación y fusión, la

36 Y, en línea con ello, la Disposición adicional primera de la proposición de ley modificaba el artículo 32 de la Ley 16/2007, de 3 de diciembre, Andaluza de la Ciencia y el Conocimiento, incluyendo expresamente al Instituto Andaluz de Salud entre los Organismos Públicos de Investigación del Sistema Andaluz del Conocimiento.

37 Este es también el régimen dispuesto en el artículo 87.2 LRJSP, que regula este tipo de operaciones para el sector público estatal y que presenta una redacción prácticamente idéntica. 
Fundación Pública Andaluza Progreso y Salud y la Escuela Andaluza de Salud Pública, S.A., no tenían que pasar por un proceso previo de disolución y liquidación ${ }^{38}$.

No existen dudas sobre la existencia de base competencial suficiente para que el Parlamento de Andalucía pudiera aprobar una ley como la propuesta. La Comunidad Autónoma de Andalucía tiene competencia exclusiva sobre la organización y estructura de sus instituciones de autogobierno (artículo 46.1 Estatuto de Autonomía para Andalucía) y sobre la estructura y regulación de sus organismos autónomos (artículo 47.1.1 ${ }^{a}$ Estatuto de Autonomía para Andalucía). Adicionalmente, el artículo 158 del Estatuto de Autonomía para Andalucía atribuye expresamente a la Comunidad Autónoma la competencia para constituir entes instrumentales para la ejecución de funciones de su competencia. En consecuencia, cabe afirmar la competencia de la Comunidad Autónoma de Andalucía para acordar, mediante ley, la transformación y fusión de dos entidades instrumentales de la Administración de la Junta de Andalucía actualmente existentes y la integración, en el nuevo ente resultante, de otros órganos y unidades administrativas ya existentes.

Cuestión distinta a la existencia de base competencial es si la operación que se pretendía acometer debía hacerse mediante ley del Parlamento o si existían alternativas normativas que permitieran abordarla de otra forma. A este respecto, debe recordarse que la Disposición final decimocuarta ("Modificación de la Ley 9/2007, de 22 de octubre, de la Administración de la Junta de Andalucía”) de la Ley 3/2019, de 22 de julio, del Presupuesto de la Comunidad Autónoma de Andalucía para el año 2019, introdujo un nuevo artículo 52.bis en la LAJA que, muy probablemente, se pretendía que fuera una pieza esencial en operaciones de racionalización y simplificación del sector público andaluz como la que, al menos en parte, perseguía la creación del Instituto Andaluz de Salud.

La interpretación de este artículo 52.bis LAJA no resulta, sin embargo, nada fácil. Destaquemos, por cuanto ahora importa, lo que establece el tenor literal de sus apartados 1 y 3 :

"1. Sin perjuicio de lo dispuesto para las agencias en el artículo 59 de esta Ley, cualquier agencia, sociedad mercantil o fundación del sector público andaluz podrá transformarse y adoptar la naturaleza jurídica de cualquiera de las entidades instrumentales de la Administración de la Junta de Andalucía anteriormente citadas.

\section{$(\ldots)$}

38 El artículo 78.3 LAJA, en la redacción dada por el artículo 14.2 de la Ley 3/2019, del Presupuesto de la Comunidad Autónoma de Andalucía para el año 2019, extiende ahora este régimen a todas las fundaciones del sector público andaluz. 
3. La transformación se llevará a cabo por decreto del Consejo de Gobierno, previo informe de las Consejerías competentes en materia de Administración Pública, Regeneración y Hacienda”.

Según se desprende de su simple lectura, el nuevo precepto permite transformar cualquier Agencia andaluza (administrativa, pública empresarial o de régimen especial), cualquier sociedad mercantil y cualquier fundación del sector público andaluz, dotándolas de la naturaleza jurídica de cualquiera de las otras dos entidades. Es decir,

- permite que una Agencia, sin dejar de ser Agencia, pase de un tipo a otro (v.gr., una Agencia administrativa podría pasar a ser Agencia pública empresarial o Agencia de régimen especial, o viceversa);

- permite que una sociedad mercantil pase a ser una Agencia (de cualquier tipo) o una fundación pública;

- y permite, finalmente, que una fundación pública pase a ser una sociedad mercantil o una Agencia (de cualquier tipo).

Estas operaciones ya eran posibles y, de hecho, algunas de ellas contaban ya con su propia regulación. Es el caso de las modificaciones o refundiciones de unas Agencias en otras, reguladas (de manera harto confusa) en el artículo 59 LAJA. Lo verdaderamente novedoso no sería la posibilidad de transformación, sino el hecho de que esta pudiera ser llevada a cabo "por decreto del Consejo de Gobierno", eliminando así la exigencia de ley y, por tanto, la necesidad de intervención del Parlamento.

De esta forma, cabría pensar que resultaba posible acometer, separadamente, la transformación de la Fundación Pública Andaluza Progreso y Salud y de la Escuela Andaluza de Salud Pública, S.A., en Agencias administrativas mediante decreto del Consejo de Gobierno (sobre la base del nuevo artículo 52.bis LAJA) y, posteriormente, proceder a su fusión como una Agencia administrativa única mediante un nuevo decreto del mismo órgano (sobre la base del artículo 59 LAJA). Esta interpretación de la norma, sin embargo, debe descartarse, debiendo afirmarse que toda la operación que la proposición de ley acometía requería que se realizara mediante norma con rango de Ley.

En efecto, la lectura del artículo 52.bis LAJA, en conexión con los artículos 56 y 59 LAJA, lleva necesariamente a la conclusión lógica de que una operación de estas características requiere norma con rango de ley, pues lo contrario conduciría a un resultado absurdo. El artículo 56 LAJA impone que la creación de las Agencias deba hacerse por ley (en el caso de Agencias administrativas y Agencias públicas empresa- 
riales) o, al menos, previa autorización de una ley (en el caso de Agencias de régimen especial), no siendo suficiente las normas de rango reglamentario. Ello se debe a la congelación de rango realizada por el artículo 56.1 LAJA, que expresamente dispone que "La creación de las agencias administrativas (...) se efectuará por ley". Este mismo precepto establece también el contenido mínimo que debe tener la ley de creación de cada Agencia administrativa o pública empresarial:

“a) El tipo de entidad que se crea, con indicación de sus fines.

b) Las peculiaridades de sus recursos económicos, y de su régimen de personal y fiscal, y cualesquiera otras que, por su naturaleza, exijan norma con rango de ley".

Pues bien, si el artículo 52.bis LAJA permitiera que el Consejo de Gobierno pudiera transformar por simple Decreto una fundación pública o una sociedad mercantil en Agencia, se estaría vaciando de todo contenido al artículo 56 LAJA, eliminando su efecto útil. En efecto, para crear una Agencia, el Consejo de Gobierno solo necesitaría crear una sociedad mercantil o una fundación pública, lo que puede hacer por sí mismo, sin necesidad de autorización legal alguna, y posteriormente adoptar un Decreto acordando su transformación en Agencia. Esta interpretación, aunque posible, debe rechazarse.

El deseo del legislador de que su intervención sea imprescindible para que puedan crearse agencias de la Administración de la Junta de Andalucía es inequívoco. El nuevo y confuso artículo 52.bis LAJA debe interpretarse, por lo tanto, en el sentido de permitir que una Agencia pueda cambiar de un tipo a otro (de acuerdo con las no menos confusas reglas del artículo 59 LAJA), o que pueda transformarse en una sociedad mercantil o en una fundación pública. Y también debe entenderse que este mismo artículo permite transformar una sociedad mercantil en una fundación pública y viceversa. Todos ellos son cambios importantes y suponen una innovación muy relevante en el ordenamiento jurídico andaluz. Lo que no resulta admisible es que se interprete que el artículo 52.bis LAJA habilita también a la transformación de sociedades mercantiles y fundaciones públicas en Agencias por decisión del Consejo de Gobierno mediante una simple norma reglamentaria y sin intervención alguna del legislador.

Por lo demás, esta interpretación del artículo 52.bis LAJA que proponemos resulta la más armónica desde una perspectiva sistemática, no solo en relación con el resto de la Ley en la que se incardina, sino también respecto al resto del ordenamiento jurídico. En este sentido, resulta esclarecedor el análisis del artículo 87 LRJSP, en el que abiertamente se inspira el artículo 52.bis LAJA. El artículo 87.1 de la ley estatal establece, como también lo hace el artículo 52.bis LAJA, que "Cualquier organis- 
mo autónomo, entidad pública empresarial, sociedad mercantil estatal o fundación del sector público institucional estatal podrá transformarse y adoptar la naturaleza jurídica de cualquiera de las entidades citadas" y el artículo 87.3 de la misma norma dispone que "La transformación se llevará a cabo mediante Real Decreto, aunque suponga modificación de la Ley de creación". Ahora bien, al determinar el régimen jurídico de estas transformaciones, el legislador estatal únicamente admite que los organismos autónomos y las entidades públicas empresariales (equivalentes a las Agencias administrativas y las Agencias públicas empresariales andaluzas) puedan ser transformadas en sociedades mercantiles o en fundaciones públicas, pero no a la inversa. De esta forma, el artículo 87.4 LRJSP ordena:

“4. Cuando un organismo autónomo o entidad pública empresarial se transforme en una entidad pública empresarial, sociedad mercantil estatal o en una fundación del sector público, el Real Decreto mediante el que se lleve a cabo la transformación deberá ir acompañado de la siguiente documentación (...)".

De ello cabe deducir, como venimos sosteniendo, que no resulta posible interpretar el artículo 57.bis LAJA en el sentido de que permita transformar sociedades mercantiles o fundaciones públicas en Agencias de la Administración de la Junta de Andalucía mediante un simple decreto del Consejo de Gobierno.

Como mucho y a lo sumo, y por los motivos expresados, esta última interpretación solo sería asumible con tantas reservas y bajo el peso de tan importantes dudas, que la simple prudencia y el respeto al principio democrático y de seguridad jurídica seguramente aconsejaban que la creación del Instituto Andaluz de Salud se realizara mediante norma con rango de ley. Dicha conveniencia se tornaba, por lo demás, en necesidad desde el momento en que la creación del nuevo ente y el establecimiento de su régimen jurídico exigían la modificación o la derogación de normas con rango de ley, tal y como se recogía en las disposiciones adicionales y derogatoria de la proposición.

\section{EL PRINCIPIO DE INSTRUMENTALIDAD Y LAS TÉGNICAS DE TUTELA ADMINISTRATIVA DESPLEGADAS SOBRE EL INSTITUTO ANDALUZ DE SALUD}

El artículo 3.1 de la proposición, en línea con el artículo 51 LAJA, del que era una transcripción parcial, establecía que el Instituto Andaluz de Salud ejercería su autonomía de gestión y administración "para el cumplimiento de sus fines con sometimiento al principio de instrumentalidad”. El mismo artículo 51 LAJA, aplicable a todas las entidades instrumentales de la Administración de la Junta de Andalucía, 
ofrece una breve indicación de lo que significa el principio de instrumentalidad, afirmando que, con arreglo a él "los fines y objetivos que se les asignan específicamente son propios de la Administración de la que dependen". Siendo una afirmación correcta, resulta, sin embargo, insuficiente para entender lo que implica el principio de instrumentalidad en toda su extensión y, lo que resulta mucho más importante, no basta para dar cuenta cabal de las potestades de tutela que permite desplegar a la Administración de la Junta de Andalucía sobre sus entes instrumentales.

La LAJA ya contiene, con carácter general, un amplio conjunto de técnicas de tutela aplicables a todas las agencias ${ }^{39}$. En el caso del Instituto Andaluz de Salud, la autonomía funcional y científica que la proposición de ley le concedía para que pudiera alcanzar sus fines y desarrollar sus funciones de una manera eficaz, tenían como contrapartida, además, un nuevo abanico de medidas de control, supervisión y reacción atribuidas a la Administración de la Junta de Andalucía. Todas ellas eran una plasmación del principio de instrumentalidad y se encontraban recogidas a lo largo del articulado de la proposición. Resultaría excesivamente tedioso y seguramente innecesario enumerar todas y cada una de tales medidas de control, tanto preventivas como reactivas, incluidas como manifestación de los poderes de tutela de la Administración de la Junta de Andalucía sobre el Instituto Andaluz de Salud. A mero título de ejemplo, cabe señalar que solo en el artículo 5.4 de la proposición se preveían hasta tres mecanismos distintos para ejercer tales controles:

- artículo 5.4.c): Necesidad de autorización de Consejo de Gobierno o de la Consejería con competencia en materia de Economía, según los casos, para constituir consorcios y sociedades mercantiles o adquirir participaciones mayoritarias en estas últimas;

- artículo 5.4.e): Necesidad de autorización de Consejo de Gobierno para participar en organizaciones, asociaciones y entidades públicas nacionales e internacionales relacionadas con su objeto;

- artículo 5.4.f): Prohibición de interponer recurso contenciosoadministrativo contra la Administración de la Junta de Andalucía.

Junto a ellos, seguramente deben destacarse, por el especial impacto que podían tener, la posibilidad de avocación del artículo 14.2 y el informe preceptivo y

39 Por ejemplo, de acuerdo con el artículo 1 16.1.b) LAJA, la revisión de oficio de los actos dictados por los "máximos órganos de gobierno" de las Agencias corresponderá al titular de la Consejería a la que se encuentren adscritas, que será también competente para resolver el procedimiento de declaración de lesividad de todos los actos anulables de la Agencia (no solo los dictados por sus máximos órganos de gobierno), conforme al artículo $116.2 .2^{\circ}$ LAJA. 
vinculante previo a la resolución del recurso de reposición prevista en el artículo 15 de la proposición.

En primer lugar, el artículo 14.2 de la proposición de ley preveía, como mecanismo de contrapeso a las importantes funciones que se atribuían a la Dirección del Instituto, una forma de avocación impropia. En principio, la técnica de la avocación, regulada con carácter general en el artículo 10 LRJSP (“Avocación”), solo puede ejercerse por parte de los órganos superiores respecto a sus órganos administrativos dependientes. En consecuencia, en la medida en que el Instituto Andaluz de Salud no se configuraba como un órgano dependiente de la Consejería, sino como una persona jurídica distinta, no cabía ejercer dicha técnica con ella, dado que no habría existido la relación jerárquica que la avocación parece exigir ${ }^{40}$. A pesar de ello, el artículo 14.2 de la proposición permitía que la persona titular de la Consejería competente en materia de salud pudiera avocar para sí el conocimiento de asuntos que correspondiera resolver a la Dirección del Instituto, en los mismos casos y con las mismas condiciones que las previstas en el artículo 10 LRJSP.

Por su parte, el artículo 15.2 de la proposición mantenía la competencia de la Dirección del Instituto para resolver los recursos de reposición interpuestos contra sus actos, pero sometiéndolos a un dictamen preceptivo y vinculante de la Viceconsejería competente en materia de salud. Es decir, del órgano al cual se encontraría adscrito el Instituto (artículo 3.2 de la proposición). De esta forma, a pesar de que entre el Instituto Andaluz de Salud y la Consejería no existía, en rigor, una relación de jerarquía, sino de tutela, se atribuía a la Viceconsejería un instrumento típico de las relaciones jerárquicas para que esta pudiera orientar y, en su caso, corregir las decisiones adoptadas por la Dirección del Instituto ${ }^{41}$.

No debe dejar de hacerse notar, sin embargo, que este mecanismo de tutela podía conllevar una posible desventaja para los administrados: los artículos 22.1.d) y 80.3 LPAC permiten la suspensión de plazo máximo legal para resolver un procedi-

40 En el mismo sentido se manifiesta, en su detallado estudio sobre el concepto de avocación impropia y las características del órgano avocante, IZQUIERDO CARRASCO, M., "Las competencias de los órganos administrativos y sus alteraciones", E. GAMERO CASADO (dir.), Tratado de Procedimiento Administrativo Común y Régimen furídico Básico del Sector Público, Tirant lo Blanch, Valencia, 2017, en especial, pp. 2808-2813.

41 Cabe señalar que el mismo resultado material podría haberse conseguido con un recurso de alzada impropio y per saltum ante la Viceconsejería. Este tipo de recursos se configuran también como instrumentos de tutela de la Administración sobre ciertos entes no encuadrados jerárquicamente dentro de su organización y, aun no siendo numerosos, tampoco son extraños en nuestro ordenamiento. Así, a mero título de ejemplo, los artículos 34.5 y 49 de la Ley 4/2019, de 19 de noviembre, de Cámaras Oficiales de Comercio, Industria, Servicios y Navegación de Andalucía, prevén la posibilidad de interponer recursos de alzada impropios ante la Consejería competente en materia de Cámaras contra ciertos actos acordados por las Cámaras de Andalucía. 
miento cuando se soliciten informes preceptivos a un órgano de la misma o distinta Administración, por un periodo de hasta tres meses. Dicha suspensión supone el triple del plazo ordinario con el que cuenta la Administración para resolver un recurso de reposición, que es de un mes (artículo 124.2 LPAG). El mecanismo planteado por el artículo 15.2 de la proposición podía dar lugar, en consecuencia, a una más que notable ampliación del plazo máximo de duración del procedimiento de recurso de reposición.

La proposición de ley completaba estos mecanismos de tutela con otros de carácter orgánico, como la creación de una Intervención Delegada dentro del Instituto (artículo 20 de la proposición) ${ }^{42}$, o vinculados a mecanismos de evaluación de actividades y funcionamiento (artículo 6 de la proposición), en los que no merece la pena detenerse.

\section{LOS FINES ENCOMENDADOS AL INSTITUTO ANDALUZ DE SALUD Y LA ATRIBUCIÓN DE POTESTADES PÚBLICAS Y OTRAS ACGIONES PARA ALGANZARLOS}

\section{La atribución genérica de potestades públicas}

El conjunto de funciones encomendadas al Instituto Andaluz de Salud (artículo 4 de la proposición) coincidía con las funciones esperables en un Organismo público de investigación y se mantenía en línea de continuidad con las que vienen desempeñando los tres entes de los que traía causa. De esta forma, el Instituto Andaluz de Salud no solo debía seguir realizando, por sí mismo, las actividades de I+D+i, de consultoría, de formación o de acreditación en materia sanitaria que constituyen la principal actividad de la Fundación Pública Andaluza Progreso y Salud y de la Escuela Andaluza de Salud Pública, S.A., sino que, además, sumaba las funciones de dirección política y de gestión administrativa en materia de investigación sanitaria de la Secretaría General de Investigación, Desarrollo e Innovación en Salud (autorización de proyectos de investigación, establecimiento de programas de ayudas y subvenciones, etc.).

Para el cumplimiento de sus objetivos y el desarrollo de sus funciones, la proposición de ley reconocía al Instituto de Salud de Andalucía todas las prerrogativas

42 Los órganos de la Intervención de la Junta de Andalucía actúan de forma exclusiva para esta, esto es, ejerciendo sus funciones de control interno y de contabilidad pública "con plena autonomía respecto de los órganos y entidades sujetos a sus potestades contables y de control” (artículo 86.2 Texto Refundido de la Ley General de la Hacienda Pública de la Junta de Andalucía). Sin embargo, ello no obsta a que puedan estar orgánicamente encuadrados dentro de otros Departamentos o entes. De hecho, para el correcto desarrollo de sus funciones, la Intervención General de la Junta de Andalucía cuenta actualmente con Intervenciones Delegadas en todas las Agencias administrativas y en todas las Agencias de régimen especial. 
atribuidas por el ordenamiento a las Administraciones públicas, atribuyéndole, además, "todas las potestades públicas precisas, salvo la expropiatoria" (artículo 5 de la proposición). Junto a ello, enumeraba, con carácter ejemplificativo, algunas de esas potestades ${ }^{43}$. Pero, al proceder a dicha enumeración, la proposición fue relativamente conservadora, refiriéndose únicamente a las siguientes tres:

“a) En materia de subvenciones, las de concesión, inspección, comprobación de la realización de la actividad y el cumplimiento de la finalidad para la que se hubieran concedido, así como las de acordar los reintegros que procedan y, en su caso, la potestad sancionadora en el ámbito de las subvenciones que conceda.

b) La de fe pública y de certificación respecto de los datos y documentos que formen parte de los expedientes que tramite.

c) Las de evaluación y acreditación profesional en materia sanitaria de competencia de la Comunidad Autónoma de Andalucía”.

La proposición seguía en este punto lo que habían hecho las normas reguladoras de otras Agencias ${ }^{44}$ y, seguramente, recogía las potestades públicas que con mayor habitualidad debería ejercer el nuevo ente. Sin embargo, la proposición podría haber sido también más audaz y explicitar la atribución de otras potestades públicas que, aún estando implícitamente atribuidas al Instituto Andaluz de Salud, podrían haber suscitado dudas respecto a su ejercicio. Tal sería el caso, paradigmáticamente, de la potestad reglamentaria.

43 De esta forma, la proposición seguía el modelo que parece marcar la LAJA, mediante una atribución doble: una primera en términos muy amplios y algo imprecisos y otra segunda mucho más específica en la que se enumeraban concretas potestades y se ofrecían algunas indicaciones sobre sus contenidos y límites. La primera de las atribuciones, de carácter genérico, suponía una transposición de lo dispuesto con carácter general en el artículo 55 LAJA para todas las agencias andaluzas, incluyendo, por tanto, a las agencias administrativas: "Dentro de la esfera de sus competencias, corresponden a las agencias las potestades administrativas precisas para el cumplimiento de sus fines, en los términos previstos en sus estatutos, salvo la potestad expropiatoria”. La segunda de las atribuciones, mucho más específica, tenía carácter meramente ejemplificativo ("entre otras") y encontraría su justificación en la necesidad de perfilar adecuadamente algunas de las potestades genéricamente atribuidas al Instituto Andaluz de Salud. Ello estaría en línea con el artículo 65.2 LAJA, de conformidad con el cual "para el desarrollo de sus funciones [las agencias administrativas] dispondrán de las potestades públicas que tengan expresamente atribuidas por sus estatutos". Se deduce de ello la necesidad de que los estatutos de cada Agencia aclaren cuáles son las potestades de las que gozan.

44 En particular, su redacción parece estar tomada, con ligerísimos cambios, de las potestades atribuidas por sus Estatutos a la Agencia Andaluza del Conocimiento (Decreto 92/2011, de 19 de abril). 


\section{2. ¿Cabe atribuir potestad reglamentaria a una Agencia administrativa?}

No ignoramos que puede causar extrañeza la atribución de la potestad reglamentaria a órganos distintos a los expresamente previstos en los artículos 112 y 119 del Estatuto de Autonomía para Andalucía, en los artículos 3, 27.9 y 44 de la Ley de Gobierno de Andalucía o en el artículo 26 LAJA. En efecto, de acuerdo con las tres normas citadas, y en apariencia, la potestad reglamentaria solo correspondería al Consejo de Gobierno y a sus miembros (Presidente, Vicepresidentes en su caso y Consejeros). Sin embargo, el hecho de que no exista previsión general de ningún otro órgano andaluz con competencia reglamentaria en estas normas no permite descartar que una ley -e, incluso, un reglamento- se la pudiese conferir para una materia determinada. Especialmente, cuando nos encontremos ante órganos reguladores o autoridades administrativas independientes, incluso Agencias. Así lo ha afirmado la mejor doctrina, que ha estimado que "una ley podrá hacerlo y hasta será conveniente que lo haga en aquellos casos en que quiera darles mayor autonomía"

Esta posibilidad se encontraba ya expresamente recogida para los organismos públicos de la Administración General del Estado, equivalentes a las agencias Andaluzas, en el antiguo artículo 42.2.2 ${ }^{\circ}$ de la Ley 6/1997, de 14 de abril, de Organización y Funcionamiento de la Administración General del Estado (LOFAGE), y se encuentra también consagrada ahora, con ligerísimos cambios, en el artículo 89.2.2 LRJSP. De conformidad con este último precepto: "Los estatutos podrán atribuir a los organismos públicos [organismos autónomos y entidades públicas empresariales] la potestad de ordenar aspectos secundarios del funcionamiento para cumplir con los fines y el servicio encomendado, en el marco y con el alcance establecido por las disposiciones que fijen el régimen jurídico básico de dicho servicio”.

De hecho, y aunque tengan carácter excepcional, en el ámbito estatal se acepta con absoluta naturalidad que órganos de naturaleza administrativa distintos al Gobierno y sus miembros puedan adoptar todo tipo de normas reglamentarias en su ámbito funcional, cuando la ley así lo prevea (artículo $129.4 .3^{\circ}$ LPAC). Y ello, a pesar de los términos tajantes en que se expresa el artículo $97 \mathrm{CE}$, tomado precisamente como modelo por el artículo 112 del Estatuto de Autonomía para Andalucía, antes indicado. Así, cabe señalar los ejemplos del Banco de España, la Comisión Nacional del Mercado de Valores o la Comisión Nacional de los Mercados y la Competencia, entre otros muchos.

45 REBOlLO PUIG, M., "El Derecho propio de Andalucía y sus fuentes", en MUÑOZ MACHADO, S. y REBOLLO PUIG, M. (Dirs.), Comentarios al Estatuto de Autonomía para Andalucía, Thomson-Civitas, Madrid, 2008, pp. 257-258. 
En el caso andaluz, resulta paradigmática la posición del Consejo Audiovisual de Andalucía, a quien se le ha atribuido una potestad reglamentaria de la que nada se dice en el artículo 131 del Estatuto de Autonomía para Andalucía, por el que se crea. Por el contrario, dicha potestad le fue atribuida por el legislador andaluz solo con dos palabras recogidas el artículo 4.17 de la Ley 1/2004, de 17 de diciembre, de creación del Consejo Audiovisual de Andalucía, de conformidad con el cual "Son funciones del Consejo Audiovisual de Andalucía (...) 17. Dictar instrucciones, decisiones y recomendaciones, así como requerimientos de información y datos necesarios para comprobar el cumplimiento de las obligaciones en materia audiovisual y de publicidad". El Consejo Audiovisual de Andalucía ha hecho uso efectivo de esta posibilidad y ha adoptado verdaderas normas bajo esta denominación de "Instrucciones" a la que se refiere el artículo ${ }^{46}$.

Podría objetarse que, aun suponiendo una excepción a la supuesta exclusividad del Consejo de Gobierno en el ejercicio de la potestad reglamentaria en Andalucía, el Consejo Audiovisual de Andalucía es un órgano estatutario. Sin embargo, incluso aceptando dicha objeción, ello no cambiaría ni el hecho de que constituye una excepción (no prevista estatutariamente) al supuesto monopolio en el ejercicio de la potestad reglamentaria del Consejo de Gobierno y sus miembros, ni al hecho de que la naturaleza del Consejo Audiovisual de Andalucía es administrativa. Y aún cabe ir más lejos: en la realidad jurídica andaluza es posible rastrear ejemplos de otras normas reglamentarias aprobadas por simples Agencias administrativas. Incluso sin previsión legal expresa ${ }^{47}$.

Atendiendo, pues, al objetivo de dotar de autonomía funcional y científica al Instituto Andaluz de Salud expresado por la proposición, podría haber estado más que justificado que, en algunos ámbitos, hubiera podido ejercer una potestad regla-

46 Sirva como ejemplo la reciente "Instrucción sobre señalización y calificación de contenidos audiovisuales televisivos", aprobada por su Pleno el 17 de noviembre de 2020 y cuyos incumplimientos pueden ser sancionados de conformidad con lo establecido en el capítulo IIII del título VI de la Ley 10/2018, de 9 de octubre, audiovisual de Andalucía.

47 Tal sería el caso de la Resolución de 25 de septiembre de 2008, del Instituto Andaluz de Administración Pública, que regula el procedimiento para la homologación de acciones formativas organizadas por promotores externos a la Administración de la Junta de Andalucía (BOJA n. ${ }^{\circ}$ 199, de 6 octubre de 2008). Se trata de una disposición aprobada por una Agencia administrativa andaluza (el Instituto Andaluz de Administración Pública), constitutiva de una verdadera norma reglamentaria, con efectos jurídicos frente a terceros, como demuestra el hecho de que pudiera ser impugnada ante los Tribunales y parcialmente anulada por estos, como de hecho ocurrió. En concreto, la STSJ de Andalucía/Sevilla de 21 de septiembre de 2011, recurso de apelación n. ${ }^{\circ}$ 289/2011, declaró la nulidad del punto segundo de esta Resolución en lo que respecta a las organizaciones sindicales como promotoras de formación, lo que dio lugar a que se dictara una nueva Resolución de 16 de enero de 2013, del Instituto Andaluz de Administración Pública, por la que se modificaba la de 25 de septiembre de 2008, por la que se regula el procedimiento de homologación de acciones formativas organizadas por promotores externos a la Administración de la Junta de Andalucía (BOJA n. ${ }^{\circ} 17$, de 24 de enero de 2013). 
mentaria limitada a su ámbito de actuación. Muy especialmente, podría haber sido apropiado que contara con dicha potestad en relación con la aprobación de las bases reguladoras de subvenciones (proyectos de investigación) cuya tramitación le era encomendada como parte de sus funciones.

Tales bases reguladoras tienen naturaleza normativa, según se desprende del artículo 17 de la Ley 38/2003, General de Subvenciones. En atención a ello, el artículo 118.1 del Texto Refundido de la Ley General de la Hacienda Pública de la Junta de Andalucía, dispone que "Las normas reguladoras de subvenciones se aprobarán por las personas titulares de las Consejerías correspondientes y serán publicadas en el Boletín Oficial de la Junta de Andalucía”. Es decir, la legislación andaluza en materia de subvenciones atribuye la potestad reglamentaria necesaria para aprobar las bases reguladoras a los titulares de las Consejerías, en lugar de al Consejo de Gobierno, lo que supone una aplicación de la excepción contemplada en el artículo 44.2 Ley de Gobierno de Andalucía ${ }^{48}$. Esta excepción, que coincide con lo previsto también en la normativa estatal, en la que se atribuye la potestad de aprobar las bases reguladoras a los Ministros mediante Orden (artículo 17.1 LGS), se justifica en atención a la menor vinculación de la actividad administrativa subvencional al principio de legalidad, al tratarse de una actividad prestacional o favorable y no limitativa de derechos, y se justifica también en el necesario conocimiento técnico que exige su aprobación.

Pues bien, atendiendo a estos mismos argumentos y, en especial, dado el elevado carácter técnico y el contenido marcadamente científico de estas bases, podría haber resultado razonable atribuir expresamente la potestad reglamentaria necesaria para aprobarlas al Instituto Andaluz de Salud. En cualquier caso, dicha potestad podía entenderse implícitamente atribuida por la amplia dicción del artículo 5.2 de la proposición, antes transcrito.

\section{Otras acciones atribuidas al Instituto Andaluz de Salud y, en especial, la posibilidad de crear entes instrumentales propios}

Junto a las potestades administrativas atribuidas al Instituto Andaluz de Salud, este contaba también con la posibilidad de ejercer otros muchos derechos y acciones amparados por el ordenamiento, muchos de los cuales fueron recogidos en el artículo 5.4 de la proposición. En ellos no era fácil identificar potestades administrativas, bien porque suponían que el Instituto Andaluz de Salud se situara en una posición más bien pasiva o típica de un administrado (beneficio de una subvención o de una

48 De acuerdo con este precepto, "Las personas titulares de las Consejerías tienen potestad reglamentaria en lo relativo a la organización y materias internas de las mismas. Fuera de estos supuestos, solo podrán dictar reglamentos cuando sean específicamente habilitadas para ello por una ley o por un reglamento del Consejo de Gobierno". 
expropiación forzosa), bien porque suponían el ejercicio de actuaciones típicas del Derecho privado (adquisición de bienes, creación de personas privadas), bien porque se relacionaban con el ejercicio de acciones procesales (defensa de sus derechos e intereses ante Jueces y Tribunales) ${ }^{49}$.

Muchas de las acciones previstas en el artículo 5.4 de la proposición no tienen especial interés. Tal sería el caso de la posibilidad de obtener subvenciones (letra a) o de gestionar sus bienes patrimoniales (letra b) ${ }^{50}$. Tampoco merece mayor consideración la posibilidad de que el Instituto Andaluz de Salud pudiera ostentar la condición de beneficiario de expropiaciones (letra g), en concordancia con lo previsto en la Ley de Expropiación Forzosa y dada la imposibilidad de ejercer por sí mismo la potestad expropiatoria, expresamente rechazada en el artículo 5.2 de la proposición. Y lo mismo cabría decir respecto a la posibilidad de que ejerciera toda clase de acciones en defensa de sus derechos ante los Juzgados y Tribunales (letra h), sin perjuicio de las prohibiciones derivadas de su naturaleza de ente instrumental de Derecho público [ex artículo 20.c) LJCA].

Mayor interés, sin embargo, podían tener otras previsiones y, muy especialmente, la posibilidad de crear entes instrumentales propios $^{51}$. El artículo 5.4.c) de la proposición, cuya redacción coincidía parcialmente con el artículo 12 LAJA, permitía al Instituto Andaluz de Salud crear dos tipos de organizaciones personificadas de gestión cuando así lo justificara la mejor consecución de sus fines: sociedades mercantiles y consorcios ${ }^{52}$.

49 Ello explica, seguramente, que puedan encontrarse preceptos muy similares en otras normas reguladoras de otros entes administrativos, como ocurre con el artículo 30.2 del Texto Refundido de la Ley Andaluza de Universidades, aprobado por Decreto Legislativo 1/2013, de 8 de enero ("De acuerdo con lo dispuesto en el ordenamiento jurídico, tendrán plena capacidad para adquirir, poseer, reivindicar, permutar, gravar o enajenar toda clase de bienes, celebrar contratos, establecer y explotar obras y servicios, obligarse, interponer los recursos establecidos y ejercitar las acciones previstas en las leyes"). Y, con mayor motivo aún, en los estatutos de otras Agencias andaluzas, en especial, las Agencias públicas empresariales y las Agencias de régimen especial.

50 Respecto a lo primero, supone una simple plasmación de la posibilidad de que las Administraciones públicas puedan ser beneficiarias de subvenciones, contenida en el artículo 2.1 LGS. Respecto a lo segundo, ello se derivaría de las posibilidades de gestión de los bienes patrimoniales consagradas en los artículos 105 y ss. LPAP.

51 En particular, la posibilidad de crear o de participar en sociedades mercantiles debía estar expresamente prevista en los estatutos del Instituto Andaluz de Salud, según exige el artículo 57.1.f) LAJA, conforme al cual, "1. El contenido de los estatutos de cualquier tipo de agencia incluirá en todo caso los siguientes extremos: (...) f) La facultad de creación o participación de sociedades mercantiles cuando sea imprescindible para la consecución de los fines asignados".

52 La redacción del precepto propuesto, muy similar a la del artículo 6.1.d) de los Estatutos de la Agencia del Conocimiento (Decreto 92/2011), era la siguiente: “c) Constituir sociedades mercantiles y consorcios, así como participar en ellos, en el supuesto en que se justifique suficientemente que es imprescindible para la consecución de sus fines asignados. Las operaciones de constitución de sociedades mercantiles y consorcios y la adquisición de participaciones mayoritarias en alguna de estas entidades privadas, habrán 
Interesa destacar que el precepto solo preveía la posibilidad de estos dos tipos de personas, omitiendo expresamente toda mención a las fundaciones. Ello podría estar en la línea del amplio consenso existente entre la mejor doctrina administrativista española acerca de la conveniencia de que el uso de fundaciones quede prohibido para las Administraciones públicas ${ }^{53}$. Y en esa misma línea parece situarse, tal vez, la nueva redacción dada al artículo 12 LAJA, que no prohíbe expresamente el uso de fundaciones, pero que claramente muestra una preferencia por la utilización de sociedades mercantiles o consorcios cuando resulta necesario crear una organización personificada de gestión con otras entidades públicas o privadas para la consecución de finalidades de interés común. Debe señalarse, sin embargo, que el ámbito de la investigación sanitaria se caracteriza, justamente, por el uso intensivo de la figura de la fundación, situación que no encuentra fácil justificación y, menos aún, después de la reforma del régimen jurídico de los consorcios operada por la LRJSP.

En cualquier caso, las posibilidades de este precepto eran muchas. En primer lugar, permitía que el Instituto Andaluz de Salud pudiera crear o participar en empresas innovadoras de base tecnológica, posibilidad expresamente prevista para los Organismos públicos de investigación (artículo 56.1 de la Ley 2/2011, de 4 de marzo, de Economía Sostenible).

En segundo lugar, y en conexión con el artículo 19 de la proposición de ley ("Colaboración y participación institucional"), hacía posible la constitución de organizaciones personificadas de gestión como forma de colaboración con "cualesquiera entidades o instituciones públicas o privadas, para el desarrollo de proyectos y programas de actuación en los ámbitos de la investigación, la innovación, la transferencia de tecnología, la evaluación, la acreditación o la formación en materia sanitaria, que permitan un mejor aprovechamiento de medios, recursos y resultados científicos, y generen conocimiento compartido".

En tercer lugar, ofrecía una posible cobertura jurídica para la creación de centros de investigación en el extranjero por parte del Instituto Andaluz de Salud, posibilidad prevista en el artículo 39.5 Ley de la Ciencia ${ }^{54}$ y ciertamente plausible atendiendo a la amplia proyección internacional con la que cuentan la Escuela An-

de ser autorizadas por el Consejo de Gobierno. Si la participación que se adquiere tiene carácter minoritario, deberá justificarse asimismo la necesidad de esa participación, pero bastará con la autorización de la Consejería con competencia en materia de Economía, con comunicación a la Consejería con competencia en materia de Hacienda, de conformidad con lo establecido en el artículo 82 de la Ley 4/1986, de 5 de mayo".

53 Especialmente categórica y razonada fue la propuesta presentada por BAÑO LEÓN, J. M., ESTEVE PARDO, J., Fernández Farreres, G., REBOLlO PUIG, M y TORNOS MAS, J. "La urgente reforma del sector público", El Cronista, n. ${ }^{\circ} 31$ (2012), p. 28.

54 En efecto, el artículo 39.5 Ley de la Ciencia prevé que "Los agentes públicos del Sistema Español de Ciencia, Tecnología e Innovación podrán crear centros de investigación en el extranjero, por sí solos 
daluza de Salud Pública, S.A., y la Fundación Pública Andaluza Progreso y Salud (fundamentalmente, aunque no solo, a través de la Agencia de Calidad Sanitaria de Andalucía - ACSA). Las dudas sobre el procedimiento que habría que seguir para crear este tipo de entes son, sin embargo, muchas y de especial envergadura ${ }^{55}$.

\section{LAS ESPECIALIDADES DEL PERSONAL INVESTIGADOR Y LA COMPLEJA SITUACIÓN DEL PERSONAL AL SERVICIO DEL INSTITUTO ANDALUZ DE SALUD}

\section{La heterogénea composición del personal al servicio del Instituto Andaluz de Salud y su peculiar sistema de fuentes}

El artículo 26.2 de la proposición distinguía las dos categorías de empleados públicos que debían formar el personal del Instituto Andaluz de Salud y precisaba su régimen jurídico cuando se tratara de personal investigador, el cual goza de especialidades expresamente previstas en el artículo 2.2 TREBEP y desarrolladas en la Ley de la Ciencia ${ }^{56}$.

o mediante acuerdos con otros agentes nacionales, supranacionales o extranjeros, que tendrán la estructura y el régimen que requiera la normativa aplicable".

55 No existe, hasta donde conocemos, una regulación específica de la Administración de la Junta de Andalucía en el exterior. Por su parte, la Ley 2/2014, de 25 de marzo, de la Acción y del Servicio Exterior del Estado, tampoco contiene regulación específica aplicable a la creación de centros de investigación en el extranjero por parte de las Comunidades Autónomas. El artículo 12 de esta ley somete a un régimen de información previa al Ministerio de Asuntos Exteriores y de Cooperación la apertura de oficinas de las Comunidades Autónomas para su promoción exterior. Sin embargo, dicho régimen no parece aplicable al supuesto aquí analizado, del mismo modo que tampoco lo sería si quien pretendiese crear un centro de investigación en el extranjero fuera una Universidad pública (cfr. art. 39.5.2 Ley de la Ciencia). En relación con la investigación en materia sanitaria, las únicas previsiones de la Ley 2/2014, de 25 de marzo, de la Acción y del Servicio Exterior del Estado se contienen en los artículos 21 y 31.1, sin que en ninguno de estos dos preceptos se contemple la posibilidad de crear centros de investigación en el exterior ni, menos aún, de someter dicha creación a ningún tipo de control previo.

En el caso andaluz, seguramente sería prudente someter la creación de este tipo de entes a la decisión de Consejo de Gobierno, requiriendo además la participación expresa de las Consejerías competentes en materia de Presidencia, Administración pública y de Hacienda. Ello sería coherente con las competencias atribuidas al Consejo de Gobierno en relación con la creación, modificación o extinción de otros entes instrumentales, así como con las competencias atribuidas a estas Consejerías en materia, respectivamente, de acción exterior, organización administrativa y estructura orgánica (artículo 33 LAJA) o control de creación de organizaciones personificadas de gestión (artículo 12.2.2 ${ }^{\circ}$ LAJA). Ello supondría, además, un régimen parcialmente coincidente con el previsto para la Administración General del Estado en el artículo 39.5.3 ${ }^{\circ}$ Ley de la Ciencia, de conformidad con el cual "En el caso de la Administración General del Estado y de las entidades a esta adscritas, la creación de centros de investigación en el extranjero se ajustará a las disposiciones que regulan la Administración General del Estado en el exterior, y se realizará previa obtención de los informes favorables del Ministerio de Economía y Hacienda y de la Presidencia".

56 En efecto, de conformidad con el artículo 2.2 TREBEP: "En la aplicación de este Estatuto al personal investigador se podrán dictar normas singulares para adecuarlo a sus peculiaridades". Muchas de 
En primer lugar, el Instituto Andaluz de Salud contaría con personal funcionario, incluyendo el personal estatutario (ex Ley 55/2003, de 16 de diciembre, del Estatuto Marco del personal estatutario de los servicios de salud). Cuando dicho personal tuviera la consideración de personal investigador, el régimen jurídico que le resultaría aplicable sería el establecido en el artículo 13.3 Ley de la Ciencia ${ }^{57}$. De acuerdo con ello, el sistema de fuentes aplicable a este personal funcionario investigador venía conformado: por el TREBEP, por la Ley de la Ciencia, por lo dispuesto en la propia Ley de creación del Instituto y por la normativa de desarrollo en materia de función pública que le resultara de aplicación [artículo 26.2.a) de la proposición].

El acceso de este personal se realizaría de acuerdo con la normativa general aplicable a los funcionarios públicos. No obstante, el artículo 27 de la proposición incluía algunas especialidades interesantes en relación con el acceso del personal funcionario investigador: su ingreso se realizaría en todo caso mediante turno libre y el sistema selectivo de acceso sería el de concurso basado en la valoración del currículo de los candidatos. Además, tanto la constitución de los órganos de selección como la realización de los procesos selectivos corresponderían al propio Instituto Andaluz de Salud. Estas especialidades, justificables una vez más por el alto nivel de especialización requerido para el ejercicio de las funciones propias de estos puestos de trabajo, se encuentran también previstas en la Ley de la Ciencia ${ }^{58}$.

Asimismo, y siguiendo de nuevo el ejemplo del otro Organismo público de investigación íntegramente andaluz, el IFAPA, el artículo 28 de la proposición creaba dos nuevas especialidades, la de Investigación Sanitaria y Biosanitaria y la de Laboratorio Sanitario y Biosanitario, dentro del Cuerpo Superior Facultativo y del Cuerpo de Técnicos de Grado Medio de la Junta de Andalucía, respectivamente ${ }^{59}$.

las especialidades se encuentran recogidas en el capítulo I ("Personal investigador al servicio de las Universidades públicas, de los Organismos Públicos de Investigación y de los Organismos de investigación de otras Administraciones públicas") del título II ("Recursos humanos dedicados a la investigación") de la Ley de la Ciencia. A ello debe sumarse el capital artículo 15.1.a) Estatuto de los Trabajadores, y la aplicación que del mismo realiza la Disposición adicional decimoquinta, apartado 2, del mismo texto legal.

57 Dispone dicho artículo que "El personal investigador funcionario se regirá por lo dispuesto en la Ley 7/2007, de 12 de abril, por lo dispuesto en esta ley, y supletoriamente por la normativa de desarrollo de función pública que le sea de aplicación”.

58 Por ejemplo, en el artículo 26.4 Ley de la Ciencia, respecto al establecimiento del concurso como sistema selectivo de acceso o en el 26.1.2 $2^{\circ}$ Ley de la Ciencia respecto a la posibilidad de atribuir al propio Instituto Andaluz de Salud la constitución de los órganos de selección y la realización de los procesos selectivos.

59 Creación que se acompañaba con la correspondiente modificación de la Ley 6/1985, de 28 de noviembre, de Ordenación de la Función Pública de la Junta de Andalucía, que ello acarreaba (Disposición adicional segunda de la proposición). El artículo 14 de la Ley 1/2003, de creación del IFAPA, ya creó, por su parte, las especialidades de Investigación Agraria y Pesquera y Desarrollo Agrario y Pesquero en los Cuerpos Superior Facultativo y de Técnicos de Grado Medio de la Junta de Andalucía. 
En segundo lugar, el Instituto Andaluz de Salud contaría también con personal laboral, que podía ser fijo o temporal. Nuevamente, cuando este personal laboral fuera personal investigador, el sistema de fuentes que le resultaría aplicable, de acuerdo con lo dispuesto en la Ley de la Ciencia, sería uno distinto al general ${ }^{60}$. En concreto, el personal laboral investigador del Instituto Andaluz de Salud debía regirse: por la Ley de la Ciencia, por el Estatuto de los Trabajadores, por lo dispuesto en la propia Ley creadora del Instituto, por las normas convencionales y por los preceptos del TREBEP que le fueran de aplicación [artículo 26.2.b) de la proposición].

Una de las consecuencias de este peculiar sistema de fuentes aplicable al personal laboral investigador era la posibilidad de que el Instituto Andaluz de Salud pudiera hacer uso de ciertos contratos laborales especiales, a los que también se refería expresamente el artículo 26.3 de la proposición. En efecto, los artículos 20 y siguientes de la Ley de la Ciencia, crearon tres modalidades contractuales a las que pueden acogerse no solo los Organismos públicos de investigación de la Administración General del Estado, sino también los OPIs de otras Administraciones Públicas, lo que permitía su aplicación al Instituto Andaluz de Salud. El artículo 20.1 de la Ley de la Ciencia se refiere a ellas como "modalidades de contrato de trabajo específicas del personal investigador", y distingue entre:

a) Contrato predoctoral, regulado en el artículo 21 Ley de la Ciencia y dirigido al personal investigador que se encuentra desarrollando su tesis doctoral ${ }^{61}$. Debe recordarse que la configuración del Instituto Andaluz de Salud como Organismo público de investigación le permitía crear o financiar escuelas de doctorado en colaboración con una Universidad (artículo 30.ter LOU) e, igualmente, habilitaba a su personal investigador en posesión del título de doctor para realizar funciones de dirección de tesis doctorales, previo acuerdo del órgano responsable del programa de doctorado de la respectiva Universidad (sección III, "Funciones de dirección de tesis doctorales", del capítulo I del título IX LOU).

b) Contrato de acceso al Sistema Español de Ciencia, Tecnología e Innovación, regulado en el artículo 22 de la Ley de la Ciencia, dirigido al

60 En particular el artículo 13.4 Ley de la Ciencia establece que "El personal investigador de carácter laboral se regirá por lo dispuesto en esta ley, en el Texto Refundido de la Ley del Estatuto de los Trabajadores, aprobado por Real Decreto Legislativo 1/1995, de 24 de marzo, y sus normas de desarrollo, y en las normas convencionales. Asimismo, se regirá por los preceptos de la Ley 7/2007, de 12 de abril, que le sean de aplicación".

61 Junto con la regulación básica de este contrato, contenida en el indicado artículo, debe tenerse en cuenta la normativa de desarrollo reglamentario de este precepto, contenida ahora en el Real Decreto 103/2019, de 1 de marzo, por el que se aprueba el Estatuto del personal investigador predoctoral en formación. 
personal investigador que ya se encuentra en posesión del título de doctor o equivalente, con una duración máxima de cinco años y orientado a obtener un elevado nivel de perfeccionamiento y especialización profesional que permitan consolidar su experiencia profesional.

c) Contrato de investigador distinguido, regulado en el artículo 23 de la Ley de la Ciencia, y ampliamente utilizado, entre otros fines, para atraer talento extranjero, para lo que existen programas específicos de ayudas públicas del Ministerio de Ciencia (Ayudas Beatriz Galindo).

Junto con estas tres modalidades de contratos de trabajo específicas, el Instituto Andaluz de Salud también podía contratar personal investigador laboral y personal técnico laboral de carácter temporal para la realización de proyectos específicos de investigación científica y técnica. Se trata de contratos de trabajo vinculados a proyectos financiados mediante ayudas obtenidas en convocatorias de concurrencia competitiva y cuya finalización se anuda, justamente, a la finalización del proyecto al que se vinculan y para el que se ha conseguido la financiación.

Este tipo de contratos se rigen, en principio, por lo previsto en el artículo 15.1.a) del Estatuto de los Trabajadores. No obstante, en el caso de contratos de investigación resultan también de aplicación las especialidades contenidas en la Disposición adicional decimoquinta del mismo texto y en la disposición adicional vigesimotercera de la Ley de la Ciencia, que impiden la aparición de trabajadores indefinidos no fijos.

En efecto, el artículo 15.1.a) ET permite la contratación de trabajadores con duración determinada, entre otros supuestos, para "la realización de una obra o servicio determinados". No obstante, el mismo precepto establece que si estos contratos sobrepasan la duración de tres años más una ampliación de doce meses, "los trabajadores adquirirán la condición de trabajadores fijos de la empresa". Esta regulación resulta profundamente perturbadora para el funcionamiento normal de la ciencia. En efecto, no son infrecuentes los casos en que una misma persona es contratada para realizar tareas de investigación con cargo a un proyecto de investigación que puede tener una duración superior a la marcada por el citado artículo. Y tampoco es infrecuente que, una vez concluido el primer proyecto, la misma persona sea contratada con cargo a un nuevo proyecto de tal forma que la suma de ambos sobrepase el término máximo marcado por la Ley. Al término del segundo proyecto, la Administración (o entidad privada) contratante, no contará con la financiación para mantener a dicha persona como trabajadora fija y, de hecho, es muy posible que no necesite más sus servicios, que solo eran requeridos en relación con el proyecto financiado. Sin embargo, la aplicación mecánica del artículo 15.1.a) y, en su caso, del artículo 15.5 
ET obligaría a dicha contratación (lo que, en el caso de la Administración pública, implicaría acudir a la figura del empleado indefinido no fijo).

Para evitar esta situación, el segundo apartado de la Disposición adicional decimoquinta ET ("Aplicación de los límites de duración del contrato por obra o servicio determinados y al encadenamiento de contratos en las Administraciones Públicas") estableció que esta regla no es aplicable a las Administraciones públicas o sus organismos públicos cuando los contratos "estén vinculados a un proyecto específico de investigación o de inversión de duración superior a tres años".

A partir de esta previsión, la Disposición adicional vigesimotercera ("Normas comunes a los contratos para la realización de proyectos y para la ejecución de planes y programas públicos de investigación científica y técnica o de innovación”) de la Ley de la Ciencia desarrolla y concreta qué tipo de contratos pueden verse afectados por esta previsión ${ }^{62}$.

\section{La integración del personal procedente de la Fundación Pública Andaluza Progreso y Salud y la Escuela Andaluza de Salud Pública, S.A.}

Todas las anteriores previsiones, en conjunto, debían dotar al Instituto Andaluz de Salud de las herramientas necesarias para desarrollar una política de personal que pudiera conjugar, por un lado, la aplicación de las normas generales de empleo público de las Administraciones públicas y, por el otro, las necesidades propias de la actividad científica y su desarrollo a través de proyectos. No obstante, debido al origen del Instituto Andaluz de Salud, resultado de la fusión y transformación de la Fundación Pública Andaluza Progreso y Salud y la Escuela Andaluza de Salud Pública, S.A., cuyo personal no tiene la consideración de empleado público, y la integración de la Secretaría General de Investigación, Desarrollo e Innovación en Salud de la Consejería de Salud y Familias, en la que existen empleados públicos funcionarios y laborales, la proposición incluía también un régimen especial y transitorio durante el que debían convivir distintos tipos de personal. Dicho régimen se establecía en la Disposición adicional cuarta de la proposición ("Régimen de integración del personal al servicio de la Fundación Progreso y Salud y de la Escuela Andaluza de Salud Pública, S.A').

La proposición de ley parecía partir de la experiencia jurídica adquirida durante el proceso de reordenación del sector público andaluz acometido durante la última década y, en particular, parecía tomar como modelo la Disposición adicional cuarta

62 Se trata de los contratos para la realización de proyectos específicos de investigación científica y técnica a que se refieren los artículos 20.2, 26.7 y 30 y el apartado 2 de la disposición adicional decimocuarta de la propia Ley de la Ciencia. 
de la Ley 1/2011, de 17 de febrero, de reordenación del sector público de Andalucía [en especial, sus apartados 1.b), 1.e) y 1.f)], y la interpretación que de la misma ha realizado el Tribunal Constitucional ${ }^{63}$.

A partir de estos antecedentes normativos, la Disposición adicional cuarta disponía, en relación con el personal que viniera prestando sus servicios en la Fundación Pública Andaluza Progreso y Salud y en la Escuela Andaluza de Salud Pública, S.A., lo siguiente:

a) Su integración en el Instituto Andaluz de Salud de acuerdo con lo establecido en el artículo 44 del Estatuto de los Trabajadores sobre sucesión de empresas, con todos los derechos y obligaciones laborales y sociales inherentes.

b) Su consideración como personal laboral del Instituto Andaluz de Salud, pero no como personal laboral de la Administración General de la Junta de Andalucía.

c) La exigencia de la participación y superación de las correspondientes pruebas selectivas de acceso libre, convocadas en ejecución de ofertas de empleo público, para poder tener acceso a la condición de personal funcionario o laboral de la Administración General de la Junta de Andalucía.

Asimismo, se planteaban dos reglas transitorias. Por un lado, que la normativa laboral de aplicación a este personal vendría determinada por sus contratos de trabajo, los convenios colectivos vigentes y los acuerdos derivados de la interpretación de los mismos, en tanto se aprobara un nuevo convenio colectivo de aplicación, y por el TREBEP en todo aquello que resultara aplicable. Por otro, que la masa salarial del personal laboral al servicio del Instituto Andaluz de Salud procedente de la Fundación Pública Andaluza Progreso y Salud y de la Escuela Andaluza de Salud Pública, S.A., no pudiera superar la masa salarial del personal de tales entidades.

63 Asimismo, la proposición parecía tener también en cuenta algunos de los "Protocolos de integración de personal", aprobados por la Secretaría General para la Administración Pública de acuerdo con la Disposición adicional cuarta de la Ley 1/2011, como los correspondientes a la Agencia Andaluza del Conocimiento (Resolución de 20 de abril, BOJA n. ${ }^{\circ} 84$ de 30 de abril, p. 10), la Agencia de Servicios Sociales y Dependencia de Andalucía (Resolución de 20 de abril, BOJA n. ${ }^{\circ} 84$ de 30 de abril, p. 12), la Agencia de Medio Ambiente y Agua de Andalucía (Resolución de 20 de abril, BOJA n. ${ }^{\circ} 84$ de 30 de abril, p. 14), la Agencia de Gestión Agraria y Pesquera de Andalucía (Resolución de 20 de abril, BOJA n. ${ }^{\circ} 84$ de 30 de abril, p. 15), la Agencia de Obra Pública de la Junta de Andalucía (Resolución de 20 de abril, BOJA n. ${ }^{\circ} 84$ de 30 de abril, p. 17) o el Servicio Andaluz de Empleo (Resolución de 20 de abril, BOJA n. ${ }^{\circ} 84$ de 30 de abril, p. 18). 
En la práctica, lo que la proposición de ley planteaba era la transformación del personal procedente de la Fundación Pública Andaluza Progreso y Salud y de la Escuela Andaluza de Salud Pública, S.A., en trabajadores indefinidos no fijos, técnica coincidente con la empleada también en los procesos de racionalización y reordenación del sector público estatal ${ }^{64}$. Esta opción jurídica ha sido aceptada por los tribunales y también, en líneas generales, por la doctrina que se ha ocupado de los aspectos laborales de estos fenómenos de reestructuración del sector público, al entender que supone una solución justa y ponderada, pues garantiza el mantenimiento del contrato de los empleados sin otorgarles la condición de fijos que, tratándose de una Administración pública, exigiría un procedimiento en el que se garantizase la igualdad, el mérito y la capacidad ${ }^{65}$.

En segundo lugar, la integración en el Instituto Andaluz de Salud del personal funcionario y laboral adscrito a la Secretaría General de Investigación, Desarrollo e Innovación en Salud, se encaraba como una mera reordenación departamental, en la medida en que este personal seguiría sometido exactamente al mismo régimen jurídico del que venía disfrutando hasta entonces ${ }^{66}$. En todo caso, y seguramente con el fin de respetar al máximo las situaciones administrativas de este personal, la Disposición adicional cuarta de la proposición establecía que, en tanto no se aprobara la relación de puestos de trabajo del Instituto Andaluz de Salud, se mantendría la actual configuración de las unidades administrativas correspondientes en la relación de puestos de trabajo de la Consejería de Salud y Familias.

64 Ley 15/2014, de 16 de septiembre, de racionalización del Sector Público y otras medidas de reforma administrativa, y en particular su artículo 5 [en el que se reguló la integración del personal procedente de la Fundación para la Proyección Internacional de las Universidades Españolas (Universidad. es) en los organismos autónomos Universidad Internacional Menéndez Pelayo y Servicio Español para la Internacionalización de la Educación (SEPIE)] y su artículo 8 [que reguló la integración del personal de la Fundación Agencia Nacional de Evaluación de la Calidad y Acreditación (ANECA), que fue suprimida, en el organismo autónomo Agencia Nacional de Evaluación de la Calidad y Acreditación (ANECA)].

65 ORTEGA BERNARDO, J., y DE SANDE PÉREZ-BÉDMAR, M., "El debate sobre la remunicipalización de los servicios públicos: aspectos jurídicos, administrativos y laborales", Anuario de Derecho Municipal 2015, pp. 61-94 y, en especial, 80-92. Más crítico, CASTILLO BLANCO, F., "Remunicipalización de servicios locales y situación del personal de los servicios rescatados", El Cronista n. o 58-59 (2016), pp. 72-95.

66 En este sentido, de la STC 236/2015, de 19 de noviembre, FJ 9.d), en la que se confirmó la constitucionalidad de la Disposición adicional cuarta de la Ley 1/2011, de 17 de febrero, de reordenación del sector público de Andalucía, se deduce que en ningún caso podía considerarse un supuesto de movilidad forzosa, pues no traería consigo la pérdida de la condición de funcionario de carrera ni afectaría a su estatus, en la medida en que este personal se seguiría rigiendo en todo caso por la normativa aplicable en materia de función pública. 


\section{La reserva del ejercicio de potestades públicas al personal funcionario}

El artículo 9.2 del TREBEP dispone que "En todo caso, el ejercicio de las funciones que impliquen la participación directa o indirecta en el ejercicio de las potestades públicas o en la salvaguardia de los intereses generales del Estado y de las Administraciones Públicas corresponden exclusivamente a los funcionarios públicos, en los términos que en la ley de desarrollo de cada Administración Pública se establezca”.

Por su parte, el ordenamiento andaluz repitió este mandato en la Disposición adicional sexta ("Ejercicio de potestades públicas") de la Ley 1/2011, de 17 de febrero, de reordenación del sector público de Andalucía. En consecuencia, como corolario a la atribución y enumeración parcial de potestades públicas al Instituto Andaluz de Salud en el artículo 5.2 de la proposición, el artículo 5.3 también reservaba al personal funcionario integrado en el nuevo ente el ejercicio de las potestades públicas y de aquellas funciones que implicaran la salvaguardia de los intereses generales.

Esta reserva resultaba de especial importancia, atendiendo a que, según acabamos de indicar, el personal al servicio del Instituto Andaluz de Salud sería especialmente heterogéneo en el momento de su creación. Ahora bien, ni dicha heterogeneidad ni, menos aún, el carácter de Agencia administrativa del Instituto Andaluz de Salud habrían sido óbice para que se le pudieran atribuir potestades cuyo ejercicio corresponda exclusivamente a funcionarios públicos.

Esta fue, sin lugar a duda, una de las cuestiones jurídicas más problemáticas durante el proceso de reordenación del sector público andaluz acometido a partir de $2011^{67}$. No obstante, como finalmente declaró la Sentencia del Tribunal Constitucional 236/2015, de 19 de noviembre de 2015, dictada en respuesta al recurso de inconstitucionalidad presentado contra la Ley 1/2011, de 17 de febrero, de reordenación del sector público de Andalucía, este tipo de previsiones, incluso cuando van referidas a agencias públicas empresariales, "no altera la reserva al personal funcionario de las funciones relacionadas con el ejercicio de potestades públicas o la salvaguarda de los intereses generales que establece la norma básica estatal" [FJ 5.3.a)].

Sencillamente, debía tenerse en cuenta la regulación contenida en la Disposición transitoria primera ("Ejercicio de funciones asignadas y adscripción funcional temporal de personal funcionario") de la proposición y, en particular, lo establecido en su apartado segundo, de conformidad con el cual

67 Para una detallada exposición de todo el proceso judicial, con una minuciosa recopilación de todos los pronunciamientos judiciales dictados en su seno, ORTIZ MALLOL, J., "La Sentencia del Tribunal Constitucional 236/2015, de 19 de noviembre de 2015 sobre la leyl/2011, de 17 de febrero, de reordenación del sector público de Andalucía (Y Damocles guardó la espada)", Revista Andaluza de Administración Pública, n. ${ }^{\circ}$ 93, 2015, pp. 177-201. 
"En tanto no se apruebe su Relación de Puestos de Trabajo, el desarrollo por parte del Instituto de Salud de Andalucía de aquellas funciones que impliquen el ejercicio de potestades públicas corresponderá exclusivamente al personal funcionario procedente de la Secretaría General de Investigación, Desarrollo e Innovación integrado en la estructura orgánica y funcional del Instituto”.

\section{CONGLUSIONES}

La malograda proposición de ley de creación del Instituto Andaluz de Salud se ocupaba de regular otras muchas cuestiones de su régimen jurídico en las que, dado su carácter excesivamente específico, no procede entrar ahora. Parte de dicha regulación era esperable (y exigible) en una norma de creación de un organismo público. Así ocurría con todos los preceptos dedicados a la organización, estructura y funcionamiento del Instituto Andaluz de Salud (en particular, todo el Capítulo II, "Organización y estructura interna", comprensivo de los artículos 8 al 20 de la proposición). Otra parte de dicha regulación, sin embargo, tenía un carácter mucho más innovador y pretendía, nuevamente, armonizar las especialidades jurídicas que los Organismos públicos de investigación presentan en algunos ámbitos con la normativa general. Tal era el caso, destacadamente, del régimen jurídico de la contratación pública (artículo 23 de la proposición) o del régimen de propiedad intelectual e industrial (artículos 31 y 32 de la proposición). No obstante, incluso dejando a un lado estas cuestiones, el análisis llevado a cabo hasta ahora permite alcanzar algunas conclusiones.

En primer lugar, la actual situación de dispersión organizativa y, muy especialmente, de sometimiento al Derecho privado de los entes encargados de ejecutar las políticas públicas andaluzas en materia de investigación sanitaria resulta injustificable y, lo que es peor, terriblemente inconveniente para los intereses públicos. Nada positivo se obtiene para el interés general del mantenimiento de esta situación, resultado de una desnortada política de "huida del Derecho Administrativo" que nunca debió producirse y de la que nada bueno cupo nunca esperar.

En segundo lugar, desde un punto de vista meramente material, la actividad investigadora presenta tantas características especiales que su realización por parte de los poderes públicos exige el establecimiento de un régimen jurídico igualmente especial. Dicho régimen jurídico especial existe. Se encuentra recogido en lo fundamental en la Ley de la Ciencia y afecta a cuestiones relacionadas con el empleo público, la contratación, la propiedad intelectual e industrial y a muchas otras. Carece de sentido, en consecuencia, actuar de espaldas a dicho régimen especial y no aprovecharlo. 
La creación de un Instituto Andaluz de Salud como ente público, que permitiese reordenar organizativamente esta parte del sector público andaluz y someterla a un régimen jurídico sistemático, ordenado y específicamente pensado para él, podría haber sido una buena forma de paliar la indeseable situación presente. El actual o los futuros gobiernos andaluces no deberían dejar en el olvido esta posibilidad. 